\title{
The Impact of the 20-50-Day Atmospheric Intraseasonal Oscillation on the Gross Primary Productivity between the Yangtze and Yellow Rivers
}

\author{
JIANYING LI \\ Division of Environmental Science and Engineering, Pohang University of Science and Technology (POSTECH), Pohang, \\ South Korea, and State Key Laboratory of Numerical Modeling for Atmospheric Sciences and Geophysical Fluid Dynamics, \\ Institute of Atmospheric Physics, Chinese Academy of Sciences, Beijing, and University of Geosciences, Wuhan, China \\ JIN-SOO KIM \\ School of GeoSciences, and National Centre for Earth Observations, University of Edinburgh, Edinburgh, United Kingdom \\ JONG-SEONG KUG \\ Division of Environmental Science and Engineering, Pohang University of Science and Technology (POSTECH), \\ Pohang, South Korea
}

(Manuscript received 28 July 2019, in final form 29 December 2019)

\begin{abstract}
Given their high carbon uptake, the terrestrial ecosystems in the East Asia summer monsoon (EASM) region play an irreplaceable role in the global carbon cycle. Because the rich vegetation growth over East Asia benefits mainly from the sufficient water supply brought by the EASM, which is characterized by a strong intraseasonal oscillation (ISO), the intraseasonal spatiotemporal variations and underlying drivers of photosynthesis activity over East Asia have been comprehensively investigated using the daily gross primary productivity (GPP) and meteorological data. Strong intraseasonal fluctuations of GPP have been identified over the area between the Yangtze and Yellow Rivers (YYR) with a magnitude of $0.4 \mathrm{gC} \mathrm{m}^{-2} \mathrm{day}^{-1}$. The mean power spectrum suggests that 20-50-day variation is the major component of the intraseasonal GPP anomalies over the YYR during the summers of 1980-2013. The 20-50-day ISO of YYR GPP anomalies is modulated by the local 20-50-day precipitation variation via soil moisture, with precipitation (soil moisture) leading GPP by 10 (7) days. The 20-50-day YYR precipitation anomalies are in turn controlled by tropical ISO signals, particularly the convective activity over the western North Pacific. This leading relationship between the 20-50-day atmospheric ISO and GPP suggests a potential for extended-range predictability of vegetation growth.
\end{abstract}

\section{Introduction}

Terrestrial gross primary productivity (GPP), the photosynthetic carbon sequestration by terrestrial ecosystems, plays an important role in the global carbon cycle (Beer et al. 2010). Le Quéré et al. (2018) suggest that approximate $34 \%$ of anthropogenic $\mathrm{CO}_{2}$ emissions are offset by the terrestrial GPP. As changes of such a $\mathrm{CO}_{2}$ flux might disturb the carbon balance of the Earth system, alter atmospheric $\mathrm{CO}_{2}$ concentration, and further cause profound climate anomalies, exploration of the spatiotemporal variability of GPP and its underlying drivers is crucial for deeply understanding the evolution

\footnotetext{
Corresponding author: Jong-Seong Kug, jskug@postech.ac.kr
}

of the global carbon cycle and accurately projecting the future changes of atmospheric $\mathrm{CO}_{2}$ concentration and climate (Cox and Jones 2008).

The spatial distribution of GPP follows the overall distribution of biomes, which is in turn primarily determined by climate conditions (Anav et al. 2015). Due to the favorable climatic conditions (e.g., abundant precipitation and high temperature), high carbon uptake by plants is observed over the tropical rain forest areas. In contrast, over the subtropical regions, the descending branch of the large-scale atmospheric circulation leads to a distinct lack of water, and thus a dip in GPP appears over the corresponding Sahara and Takla Makan deserts (Anav et al. 2015; Zhang et al. 2017). Within the same latitude belt, there is also a vast area of rich vegetation 
growth from eastern China to the southern parts of the Korean peninsula and Japan, and these areas are characterized by diverse ecosystems: forests, wetlands, grasslands, and croplands (Hirata et al. 2008; Yao et al. 2018). Within this East Asia area, both forest and cropland ecosystems exhibit high carbon uptake, even comparable to that of the Asian tropical forest (Yu et al. 2013). Moreover, the East Asia subtropical forest is characterized by a young age structure (Yu et al. 2014), indicating the potential for further increase of carbon uptake in the future. Considering its increasingly important role in the global carbon cycle (Piao et al. 2009; Pan et al. 2011; Yu et al. 2014), studying the variability of the East Asian ecosystems and the driving factors is of great importance.

The formation of such rich vegetation growth within the subtropical latitude belt is primarily due to the sufficient water supply brought by the East Asian summer monsoon (EASM; Hirata et al. 2008; Chen et al. 2013; Yu et al. 2014). Starting in mid-May, warm and moist southwesterlies from the tropical Indian Ocean, South China Sea (SCS), and tropical western Pacific advance into East Asian continents in a stepwise fashion (Lau et al. 1988; Ding and Chan 2005). This results in rainy stages over southern China in mid-May, the Yangtze River Valley and southern Japan in mid-June, and northeastern China and the Korean peninsula in mid-July, respectively (He et al. 2008; Zhu et al. 2011), thereby relieving the water stress and nurturing the subtropical ecosystems.

Intraseasonal oscillation (ISO) is an important component of the EASM (e.g., Lau and Chan 1986), with the abovementioned rainy stages all characterized by strong alternations between wet and dry spells on a time scale between day-to-day weather and seasonal-mean climate (e.g., Chen et al. 1988; Mao et al. 2010). Previous works have demonstrated clearly that the annual mean climate conditions exert a strong control on the vegetation growth over East Asia, with temperature, precipitation, and solar radiation jointly modulating the interannual variability of annual mean GPP (Kondo et al. 2017; Yao et al. 2018). However, it remains unclear whether GPP over East Asia exhibits any intraseasonal fluctuation in response to the intraseasonal climatic anomalies. Valsala et al. (2013) identified a strong intraseasonal variability in $\mathrm{CO}_{2}$ fluxes over India and revealed its close relationship with the tropical ISOs over the Indian monsoon region, implying that terrestrial vegetation productivity indeed responds on the intraseasonal time scale to the changes of climate conditions. Therefore, it is logical to explore whether the intraseasonal anomalies associated with ISO of the EASM also lead to an intraseasonal fluctuation of GPP over East Asia.
Moreover, the ISO-related anomaly is a major driver of extreme disasters that exert severe impacts on socioeconomic activity over East Asia (Li and Zhou 2015; Chen and Lu 2015; Chen and Zhai 2017), such as the disastrous Yangtze flood in the summer of 1998 ( $\mathrm{Li}$ and Mao 2018b) and the record-breaking heat wave over South Korea in 2016 (Hsu et al. 2017). As the terrestrial ecosystem is highly vulnerable to persistent climate extremes (Reichstein et al. 2013; Frank et al. 2015), it is of great significance to explore the influence of ISO-related climatic anomalies on the vegetation productivity over East Asia. Additionally, East Asia possesses a large area of cropland that requires human management. As ISO is the primary source of extended-range forecasting, studying the influence of atmospheric ISO on GPP might provide an improvement in crop yield forecasts on the intraseasonal time scale, thus optimizing agricultural management strategy.

The goal of the present study is to investigate how intraseasonal climatic anomalies in association with ISO of the EASM influence GPP variability. This is in order to better understand how the EASM exerts control over the terrestrial ecosystem. Section 2 describes the data and methods. The spatial and temporal variation of GPP over East Asia is presented in section 3. Section 4 reveals the relative importance of precipitation, temperature, and solar radiation on GPP over the area between the Yangtze and Yellow Rivers (YYR; $30^{\circ}-40^{\circ} \mathrm{N}$, $105^{\circ}-120^{\circ} \mathrm{E}$ ) on the intraseasonal time scale. Section 5 further reveals how precipitation controls the GPP via the modulation of soil moisture on the intraseasonal time scale. The source of the key intraseasonal precipitation anomalies over the YYR is presented in section 6. Finally, a summary and discussion are given in section 7 .

\section{Data and methods}

\section{a. Data}

High horizontal resolution $\left(0.5^{\circ} \times 0.5^{\circ}\right)$ daily GPP data derived from the FLUXCOM products (Jung et al. 2017) were used to represent the photosynthesis activity over East Asia. The global GPP dataset were obtained through a set of data-driven methods. Two partitioning algorithms (Lasslop et al. 2010; Reichstein et al. 2005) were applied to estimate daily GPP based on 224 FLUXNET-based flux tower sites. Subsequently, three machine learning algorithms, random forest (Breiman 2001), artificial neural network (Haykin 1998), and multivariate adaptive regression splines, were trained on the obtained GPP estimates with meteorological data (Tramontana et al. 2016) to obtain the relationship between GPP and the local climatic drivers for the corresponding plant functional type. Finally, the trained 
machine learning models were run with the global climate variables derived from the CRUNCEPv6 dataset (ftp://ftp.bgc-jena.mpg.de/pub/outgoing/FluxCom/Carbon Fluxes_v1_2017/RS+METEO/CRUNCEPv6/), a merged product of variables from the Climate Research Unit (CRU) observation-based monthly variables (New et al. 2000) and the 6-hourly National Centers for Environmental Prediction variables, as input data, thereby upscaling the GPP estimates from tower sites to the global scale. While most other existing datadriven GPP only has a coarser temporal resolution (e.g., monthly or eight-daily) or shorter time period, the above-mentioned GPP data from the FLUXCOM product have a finer temporal resolution (daily) and are available dating back to 1980 . As abrupt variations usually occur during the phase transition on the intraseasonal time scale, the daily GPP derived from FLUXCOM have an obvious advantage over other monthly or eight-daily GPP data in detecting the intraseasonal fluctuation of vegetation productivity. The three machine learning algorithms combined with the two partitioning methods provide six sets of global GPP estimates. Each of the six sets is viewed as an ensemble and the ensemble mean of these six sets was calculated to reduce the ensemble randomness. All the analyses of the present paper are based on the obtained ensemble mean (average) GPP.

Considering the close linkage between chlorophyll fluorescence and carbon assimilation rate (Genty et al. 1989; Krause and Weis 1991), a 4-day-average spatially contiguous solar-induced chlorophyll fluorescence (SIF) dataset (Zhang et al. 2018), which was derived by training a neutral network with surface reflectance from the Moderate-Resolution Imaging Spectroradiometer (MODIS) and SIF from the Orbiting Carbon Observatory$2(O C O-2)$, was also included to evaluate the uncertainty of the results revealed by FLUXCOM GPP. To explore how photosynthetic activity responds to the distinctive climatic anomalies on the intraseasonal time scale, the allsky SIF dataset, which is available from 2001 to 2016, was used in this study.

Precipitation, 2-m air temperature, and incident solar radiation were derived from the CRU-JRA55 dataset (Harris et al. 2014; Kobayashi et al. 2015; University of East Anglia Climatic Research Unit 2019), which was constructed by combining data from the Japanese 55-year Reanalysis (JRA-55) data produced by the Japanese Meteorological Agency with the CRU variables. The CRU-JRA55 dataset is at $0.5^{\circ} \times 0.5^{\circ}$ spatial and 6-hourly temporal resolution and was aggregated to daily average in this study. Daily soil moisture data derived from the Global Land Evaporation Amsterdam Model (GLEAM;
Martens et al. 2017) were used to explore the ways that intraseasonal precipitation anomalies influence GPP. This dataset has a high horizontal resolution of $0.25^{\circ} \times$ $0.25^{\circ}$. To further investigate the sources for intraseasonal climatic anomalies that significantly affect the vegetation productivity over East Asia, daily atmospheric circulation data were obtained from the National Centers for Environmental PredictionDepartment of Energy (NCEP-DOE) Atmospheric Model Intercomparison Project (AMIP-II) reanalysis products (Kanamitsu et al. 2002), with a horizontal resolution of $2.5^{\circ} \times 2.5^{\circ}$ and 17 levels in vertical. The NCEP-DOE Reanalysis II dataset was chosen for its good representation of intraseasonal circulation anomalies in both the tropics and the mid-high latitudes (e.g., Lee et al. 2013; Hu et al. 2016). Daily outgoing longwave radiation (OLR) data from the National Oceanic and Atmospheric Administration (NOAA) polar-orbiting satellites were used as a proxy for deep convection in association with tropical ISO (Liebmann and Smith 1996), with a horizontal resolution of $2.5^{\circ} \times 2.5^{\circ}$. All the meteorological data listed above were extracted for the same time period between the years 1980 and 2013.

\section{b. Methods}

Following the method of Li et al. (2015), intraseasonal anomalies for GPP/SIF and the related climate forcing factors were calculated via the following two steps: 1) subtracting the time mean and the first three harmonics of the daily-resolved climatology to remove the seasonal cycle and 2) removing the synoptic variability by applying a 10-day running average. To represent the spatial distribution of intraseasonal vegetation productivity over East Asia, standard deviations of intraseasonal GPP/SIF anomalies at each grid within the EASM area were calculated, with the strongest intraseasonal fluctuation identified over the YYR (as discussed in section 3). To further detect the predominant period of YYR GPP/SIF variability, power spectrum analysis was applied to the intraseasonal GPP/SIF anomalies area-averaged over the YYR during each summer. Mean power spectra were then calculated by taking the average of the individual power spectra for the 34 summers from 1980 to 2013, thereby yielding the common periodicity. As the significant power spectra were mostly concentrated within the frequency band of 20-50 days, a 20-50-day Lanczos filter was further applied to the intraseasonal anomalies of GPP/SIF and other meteorological variables to extract the corresponding 20-50-day component.

To identify the dominant factor modulating the YYR GPP on the 20-50-day time scale, lag correlations between the filtered GPP and climate variables (precipitation, 

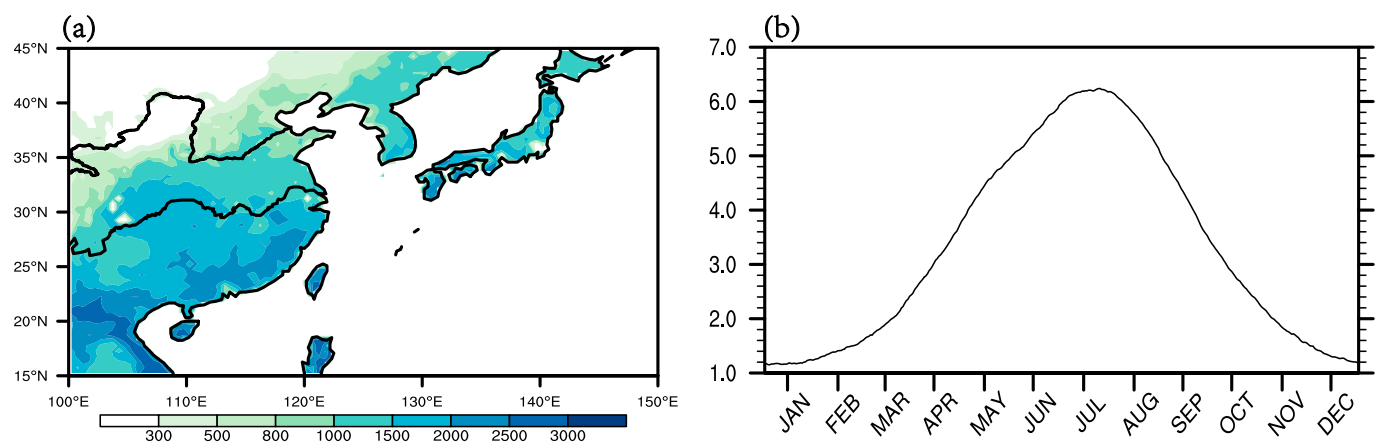

(c)
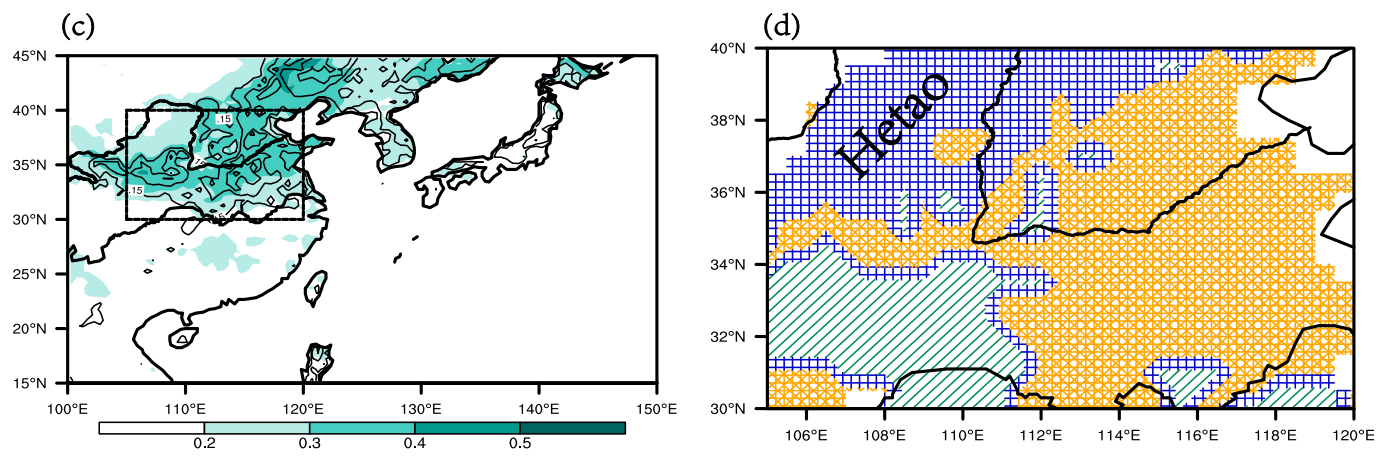

FIG. 1. (a) Distribution of annual GPP (shading; $\mathrm{gC} \mathrm{m}^{-2} \mathrm{yr}^{-1}$ ) over East Asia during the period of 1980-2013. Also shown is (b) the seasonal variation of GPP (solid line; $\mathrm{gC} \mathrm{m}^{-2} \mathrm{day}^{-1}$ ) area averaged over the East Asia region. (c) Distribution of the standard deviation of intraseasonal GPP (shading; $\mathrm{gC} \mathrm{m}^{-2}$ day $^{-1}$ ) and NEE (contours; $\mathrm{gC} \mathrm{m}^{-2} \mathrm{day}^{-1}$; the contours start from 0.15 and have an interval of 0.02 ) over East Asia during the boreal summer (1 Jun-31 Aug) of 1980-2013. The dashed rectangle in (c) denotes the area between the Yangtze and Yellow Rivers (YYR; $30^{\circ}-40^{\circ} \mathrm{N}, 105^{\circ}-120^{\circ} \mathrm{E}$ ) over which the area-averaged $20-50$-day filtered GPP anomalies is produced in Fig. 4. (d) Over the key YYR, three main land-cover types are labeled with different fill patterns, with green slashes denoting mixed forest, a blue checkered pattern for grassland, and a yellow cross pattern for cropland. The thickened curves show the locations of the Yangtze and Yellow Rivers, with the southern curve indicating the Yangtze River and the northern one denoting the Yellow River.

temperature, or solar radiation) were calculated at each grid within the target domain, with the time lag ranging from 15 to 0 days. Furthermore, we defined the 20-50-day filtered GPP anomalies averaged over the YYR as the GPP index (GI) and conducted a composite analysis to further investigate how the dominant factor influences the photosynthetic carbon uptake over the YYR on the 20-50-day time scale. Based on the GI, a high (low) GPP event is defined as a cycle satisfying the following two criteria: 1 ) the magnitude of the maximum (minimum) GI is larger than its one standard deviation, and 2) as we focus on the climatic drivers of vegetation productivity during the boreal summer, the 21 days preceding the maximum (minimum) GI must be included in the summertime series (1 June to 31 August of 1980-2013). Accordingly, 47 high GPP events and 48 low GPP events were identified during the summers of 1980-2013. In each high (low) event, the date of the maximum (minimum) GI occurrence is designated day 0 , with the days before day 0 labeled as negative days (Yang et al. 2017). Daily composites were generated for the time span from day -21 to day 0 . As the composites of low
GPP events nearly exhibit a mirror image of the high GPP counterparts, we only display composites for high GPP events in section 4 for brevity. Similar composites were also conducted based on SIF data to further justify the results from FLUXCOM GPP.

\section{Spatial-temporal variation of GPP over the EASM region}

\section{a. Overview of GPP over the EASM region}

Following the distribution of biomes, the annual GPP exhibits a descendant gradient from south to north over East Asia (Fig. 1a), with the highest carbon uptake in the evergreen broadleaf forest over the Indo-China Peninsula in excess of $2500 \mathrm{gC} \mathrm{m}^{-2} \mathrm{yr}^{-1}$, and the lowest in the grassland over Inner Mongolia, less than 300 $\mathrm{gC} \mathrm{m}^{-2} \mathrm{yr}^{-1}$. The spatial distribution of GPP displayed in Fig. 1a is consistent with that derived from the highresolution GPP dataset developed by Yao et al. (2018), which includes data from 40 flux sites over East Asia [see Figs. 2 and S3 in Yao et al. (2018)]. 
TABLE 1. Correlation (Cor) of 5-day running-mean daily climatology between GPP from the FLUXNET site and the FLUXCOM GPP at the nearest grid. The daily climatology is calculated from the available period. In the land-cover column, GRA is grasslands, WET is wetland, MF is mixed forest, ENF is evergreen needle forest, and EBF is evergreen broadleft forest.

\begin{tabular}{lccccc}
\hline \hline Site name & Period & Lat $\left({ }^{\circ} \mathrm{N}\right)$ & Lon $\left({ }^{\circ} \mathrm{E}\right)$ & Land cover & Cor \\
\hline CN-HaM & $2002-04$ & 37.4 & 101.2 & GRA & 0.97 \\
CN-Ha2 & $2003-05$ & 37.6 & 101.3 & WET & 0.97 \\
CN-Cng & $2007-10$ & 44.6 & 123.5 & GRA & 0.97 \\
CN-Cha & $2003-05$ & 42.4 & 128.1 & MF & 0.97 \\
CN-Qia & $2003-05$ & 26.7 & 115.1 & ENF & 0.93 \\
CN-Din & $2003-05$ & 23.2 & 112.5 & EBF & 0.54 \\
JP-SMF & $2002-06$ & 35.3 & 137.0 & MF & 0.95 \\
\hline
\end{tabular}

Due to the remarkable seasonal cycle of the East Asian monsoon, GPP over East Asia also displays a strong seasonality (Fig. 1b). Benefitting from the warm and moist air brought by the EASM from the oceans, plants over East Asia rapidly grow in spring and summer, with the maximum photosynthesis rate in summer (June-August) almost 6 times that in winter. We compared the seasonal cycle of FLUXCOM GPP with that derived from GPP in FLUXNET sites by calculating the correlation of 5-day running-mean daily climatology. Seven sites were selected for comparison based on two criteria: 1) location of the site within the East Asian monsoon region $\left(20^{\circ}-40^{\circ} \mathrm{N}, 100^{\circ}-145^{\circ} \mathrm{E}\right)$ and 2$)$ availability of GPP data for at least 3 years. At six out of seven sites, the correlation coefficient of seasonal cycle between two datasets is above 0.9 (Table 1), indicating that the FLUXCOM GPP also well captures the seasonal cycle of vegetation productivity over East Asia.

Therefore, we deemed that it is appropriate to use FLUXCOM GPP to understand the spatiotemporal variation of photosynthetic carbon uptake over East Asia. Since boreal summer is the growing season for plants in East Asia and strong intraseasonal fluctuations are identified in multiple variables of EASM, the following sections are focused on how photosynthetic carbon uptake responds to the intraseasonal anomalies of EASM during the summer.

\section{b. Intraseasonal GPP anomalies over the EASM region}

Standard deviation is an important measure to quantify variability. To represent the intraseasonal variability of photosynthetic carbon uptake over East Asia, Fig. 1c displays the standard deviation of intraseasonal GPP anomalies. The strongest GPP variabilities are observed over the YYR and Northeast China, with a magnitude of $0.4 \mathrm{gCm}^{-2} \mathrm{day}^{-1}$. These fluctuations further lead to changes in the net ecosystem exchange
(NEE) of carbon; therefore, the spatial distribution of the intraseasonal standard deviation of NEE highly resembles that of GPP, with the largest NEE variabilities also appearing over the YYR and Northeast China (Fig. 1c). We also calculated the NEE variances explained by GPP changes over these two centers and found that $50 \%$ (49\%) of the changes in NEE over the YYR (Northeast China) can be attributed to the variations in GPP. Therefore, the intraseasonal GPP variability not only reveals the changes in vegetation productivity but also indicates the intraseasonal fluctuations of net carbon exchange over East Asia. Since strong intraseasonal fluctuations of SIF are also identified over the YYR but not over Northeast China (Fig. 10c; as discussed in section 7), the YYR is selected as a key domain to study intraseasonal variability of photosynthetic activity in the present study.

To identify the predominant intraseasonal periodicity of GPP over the YYR, power spectrum analysis is applied to the intraseasonal GPP anomalies averaged over the YYR for each summer of 1980-2013. Figure 2a displays the mean power spectrum averaged over the 34 summers. Compared to the Markov red noise spectrum, significant intraseasonal GPP anomalies were identified within the frequency band of 20-50 days. Although significant power spectra are observed in a broad 12-50-day frequency band in the mean power spectrum of precipitation, temperature, and solar radiation over the YYR (Figs. 2b-d), the peak of significant power spectra appears within the 20-50-day frequency band, indicating that the 20-50-day ISO is also an important component of climatic factors over the YYR. As a result, we mainly focus on how ISO-related intraseasonal anomalies influence the YYR vegetation productivity on the 20-50-day time scale in the following sections.

\section{Dominant climatic driver to the 20-50-day GPP anomalies over the YYR}

To explore the relative importance of precipitation, temperature, and solar radiation on GPP over the YYR on the 20-50-day time scale, the lag-correlation coefficients between the 20-50-day filtered GPP and the preceding precipitation (temperature or solar radiation) were calculated at each grid within the EASM area from the time lag of 15 to 0 days. Over most areas of the YYR, GPP is positively correlated with the local precipitation, with correlation coefficients in excess of 0.4 , which are significant at the $95 \%$ confidence level (Fig. 3a). The correlation coefficient between the precipitation and GPP peaks when the local precipitation leads the GPP by $8-9$ days over forest and grassland and slightly longer 
Mean Power Spectrum
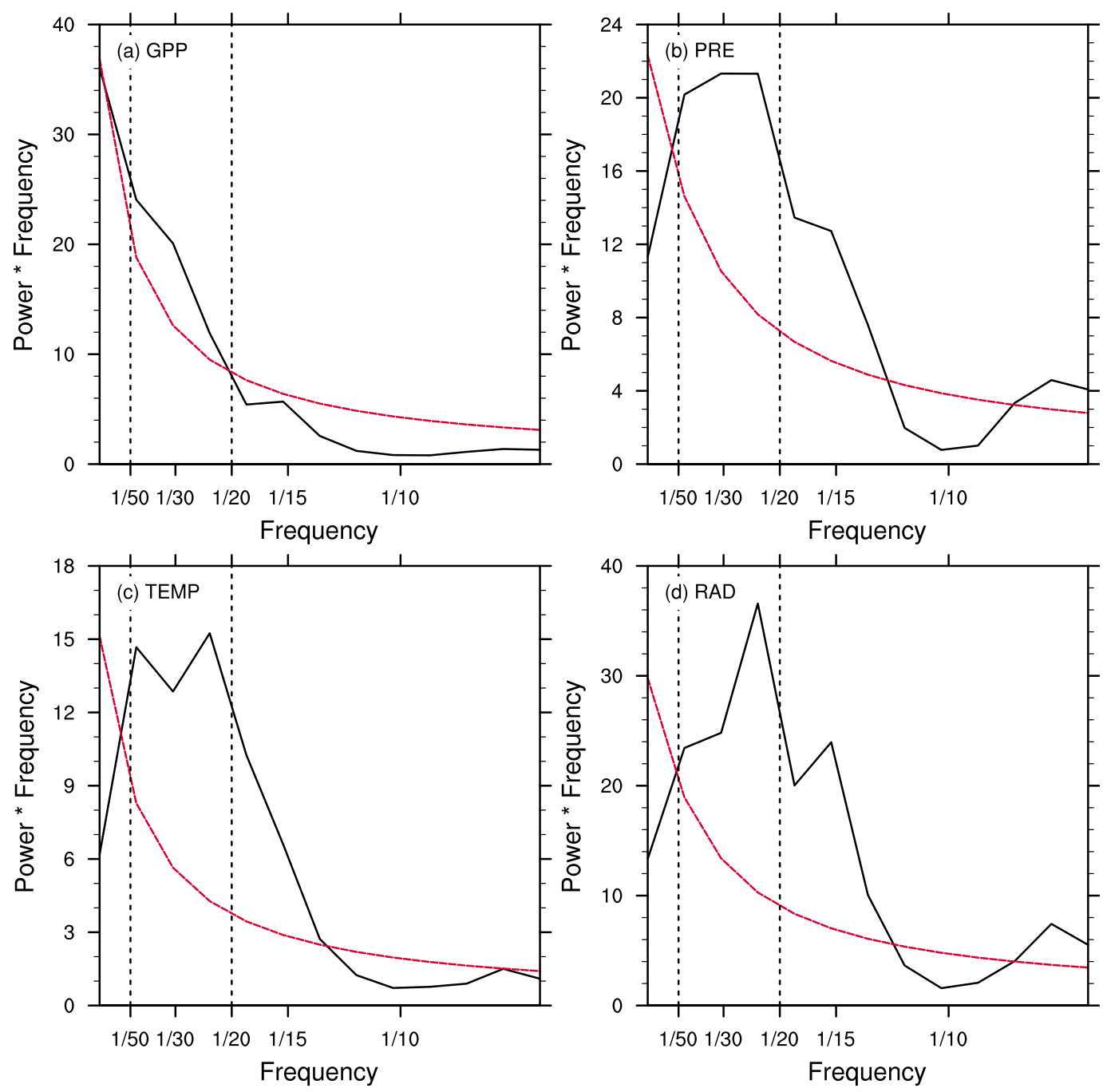

FIG. 2. Mean power spectrum of the intraseasonal (a) GPP, (b) precipitation, (c) temperature, and (d) solar radiation over the area between the Yangtze and Yellow Rivers (YYR; $30^{\circ}-40^{\circ} \mathrm{N}, 105^{\circ}-120^{\circ} \mathrm{E}$ ), calculated as the average of the individual power spectrum for each of the 34 summers during the period of 1980-2013. Also displayed is Markov red noise spectrum (red dashed line) for each mean power spectrum. The $x$ abscissa stands for frequency, and the $y$ abscissa represents the power spectrum times the corresponding frequency. The dashed lines indicate the significant frequency band of intraseasonal GPP anomalies over the YYR.

(10-11 days) over cropland (Fig. 3d), indicating that a positive precipitation anomaly is a significant precursor for enhanced photosynthetic carbon uptake over the target YYR.

Significant negative correlations between the 20-50-day filtered GPP and solar radiation are found over the forest and grassland of the YYR (Fig. 3b), with correlation coefficients peaking when solar radiation leads GPP by 8-9 days (Fig. 3e). However, vegetation photosynthesis responds to the change of solar irradiance with a time scale of seconds to minutes (Pearcy et al. 1996); therefore, GPP is expected to evolve in phase with solar radiation instead of with a long time lag. Since the incident solar radiation is closely related to the occurrence of precipitation, with more (less) solar radiation accessible to plants during sunny (rainy) days, the negative correlation and long lead of solar radiation as displayed in Figs. $3 \mathrm{~b}$ and $3 \mathrm{e}$ might be attributed to the precipitation anomalies, which also lead GPP by 8-9 days. Moreover, as incident solar radiation plays a critical role in surface energy balance, the occurrence of positive precipitation anomalies and the accompanied reduced incident solar radiation lead to a decrease in surface temperature and further result in the reduction 


\section{Lag-correlation Analysis}
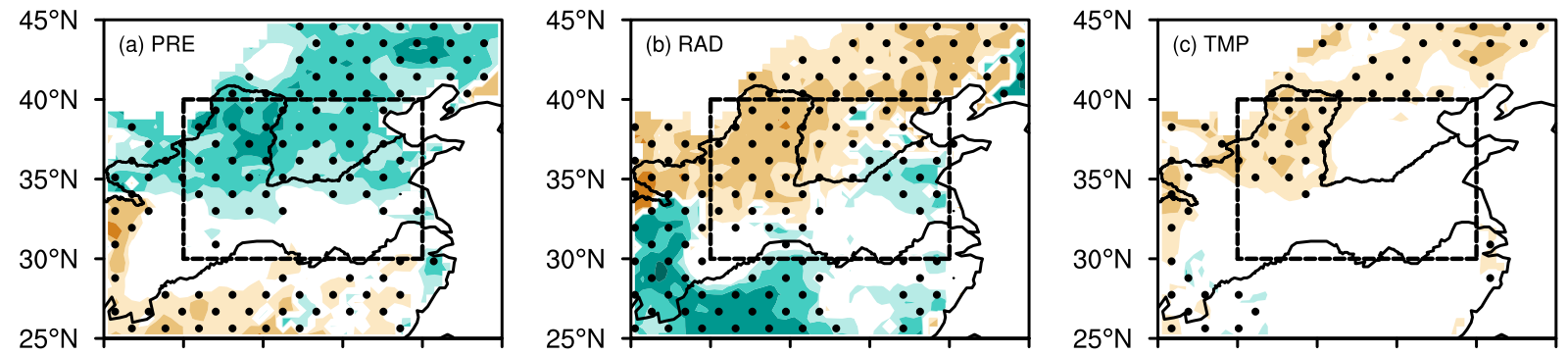

$100^{\circ} \mathrm{E} 105^{\circ} \mathrm{E} 110^{\circ} \mathrm{E} 115^{\circ} \mathrm{E} 120^{\circ} \mathrm{E} 125^{\circ} \mathrm{E}$

$100^{\circ} \mathrm{E} 105^{\circ} \mathrm{E} 110^{\circ} \mathrm{E} 115^{\circ} \mathrm{E} 120^{\circ} \mathrm{E} 125^{\circ} \mathrm{E}$

$100^{\circ} \mathrm{E} 105^{\circ} \mathrm{E} 110^{\circ} \mathrm{E} 115^{\circ} \mathrm{E} 120^{\circ} \mathrm{E} 125^{\circ} \mathrm{E}$
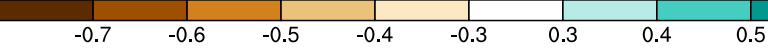

\section{$0.6 \quad 0.7$}
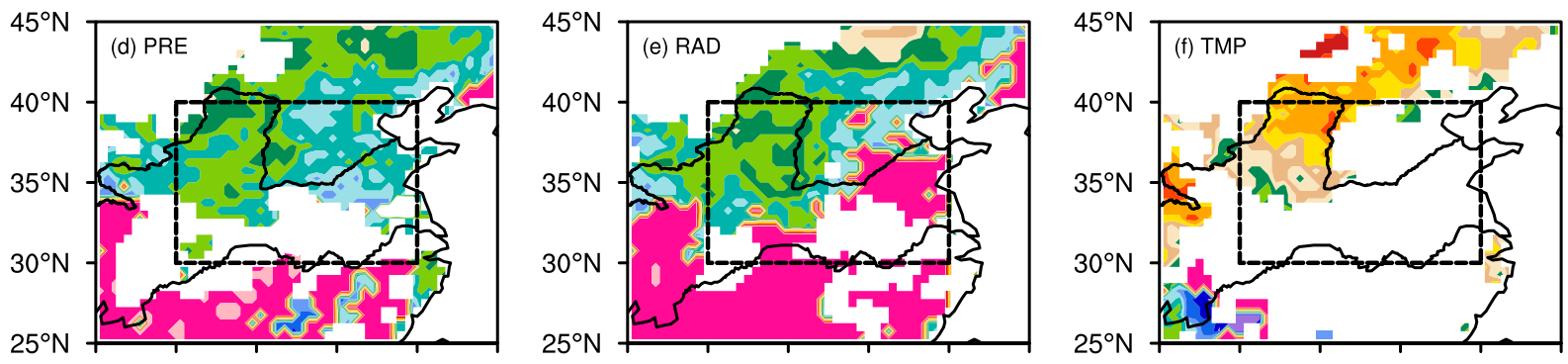

$100^{\circ} \mathrm{E} 105^{\circ} \mathrm{E} 110^{\circ} \mathrm{E} 115^{\circ} \mathrm{E} 120^{\circ} \mathrm{E} 125^{\circ} \mathrm{E}$

$100^{\circ} \mathrm{E} 105^{\circ} \mathrm{E} 110^{\circ} \mathrm{E} 115^{\circ} \mathrm{E} 120^{\circ} \mathrm{E} 125^{\circ} \mathrm{E}$

$100^{\circ} \mathrm{E} 105^{\circ} \mathrm{E} 110^{\circ} \mathrm{E} 115^{\circ} \mathrm{E} 120^{\circ} \mathrm{E} 125^{\circ} \mathrm{E}$

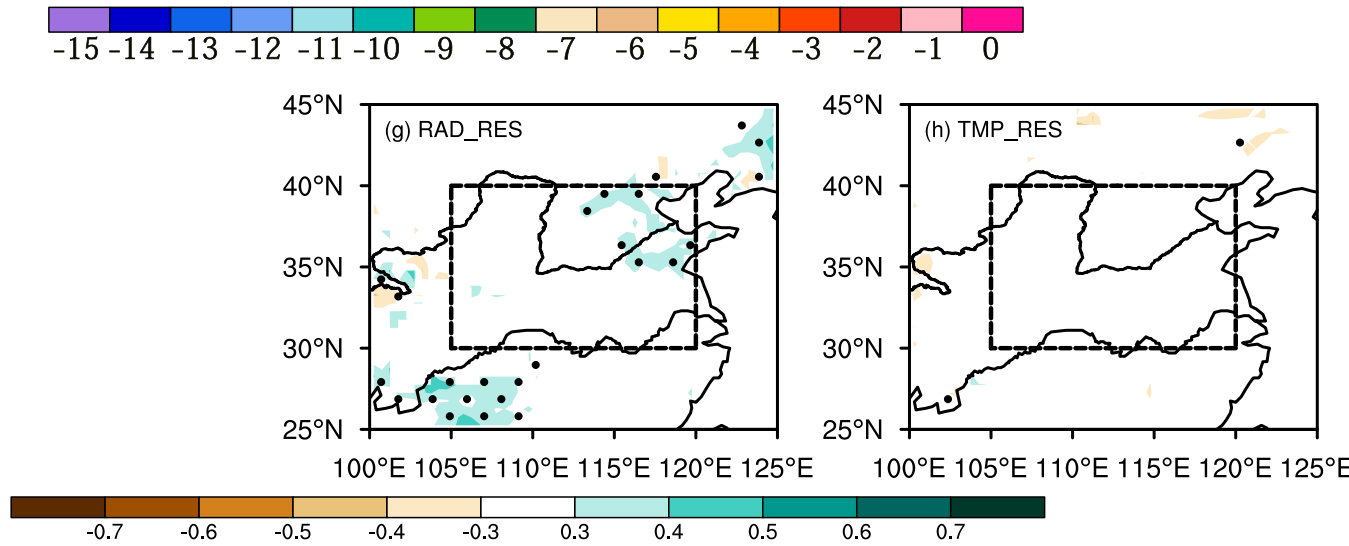

FIG. 3. (a) The maximum lag-correlation coefficient between the 20-50-day filtered GPP and precipitation anomaly at each grid over eastern China within the time lag from 15 to 0 days during the boreal summer (1 Jun-31 Aug) of 1980-2013. Stippling indicates the region where the maximum lag-correlation coefficient is significant at the 95\% confidence level. (d) Also shown is the time lag corresponding to the maximum lag-correlation coefficients in (a), with zero indicating GPP evolves with precipitation simultaneously and negative values implying precipitation leads GPP on the 20-50-day time scale. The time lag is displayed only when the corresponding maximum lag-correlation coefficient is significant. The thickened curves show the locations of the Yangtze and Yellow Rivers, with the southern curve indicating the Yangtze River and the northern one denoting the Yellow River. The rectangle denotes the area between the Yangtze and Yellow Rivers (YYR; $30^{\circ}-40^{\circ} \mathrm{N}, 105^{\circ}-120^{\circ} \mathrm{E}$ ). (b),(e) As in (a) and (d), respectively, but for the lag correlation of solar radiation. (c),(f) As in (a) and (d), respectively, but for the lag correlation of temperature. (g),(h) As in (b) and (c), but for the result of partial lag correlation between the 20-50-day filtered GPP and solar radiation or temperature, with the influence of precipitation removed.

of 2-m atmospheric temperature through decreased sensible heat fluxes. Therefore, although significant negative correlations are identified between the filtered GPP and temperature over the Hetao area $\left(34^{\circ}-40^{\circ} \mathrm{N}\right.$, $105^{\circ}-110^{\circ} \mathrm{E}$; Fig. $\left.3 \mathrm{c}\right)$, contrary to the previous works that positive (negative) temperature anomalies tend to increase (decrease) the photosynthetic activity of grassland over eastern China (He et al. 2007; Zhang et al. 2019), it might indicate the influence of precipitation on 2-m temperature and GPP, rather than the direct 
influence of intraseasonal temperature anomalies on vegetation productivity. To examine whether intraseasonal temperature and solar radiation anomalies could influence the vegetation productivity independent of precipitation, Figs. $3 \mathrm{~g}$ and $3 \mathrm{~h}$ further display the maximum partial lag-correlation coefficients between the 20-50-day filtered GPP residual and temperature/ solar radiation anomalies. For each grid, the time series of GPP residual anomalies is calculated as the time series of 20-50-day filtered GPP anomalies minus the time series of 20-50-day filtered GPP anomalies regressed by the 20-50-day filtered precipitation anomalies with $t_{\text {lag }}$, where $t_{\text {lag }}$ is the time lag corresponding to the maximum lag-correlation coefficients between GPP and precipitation, as shown in Fig. 3d. No significant correlation is found between GPP and either temperature or solar radiation over the forest and grassland when the influence of precipitation is removed, indicating that direct influence of intraseasonal temperature/solar radiation anomalies on photosynthetic carbon uptake at these two ecosystems is relatively weak.

For the cropland over the eastern part of the North China Plain (NCP; $\left.32^{\circ}-40^{\circ} \mathrm{N}, 100^{\circ}-120^{\circ} \mathrm{E}\right)$, a winter wheat-summer maize double cropping system is operated, with maize that is sown in mid-June and harvested at the beginning of October as the staple crop during our study period. Since boreal summer is the rainy season for the NCP, natural precipitation is largely sufficient for summer maize (Binder et al. 2007). To guarantee the crop production, extensive management techniques are also applied to this cropland, including irrigation in case of persistent dry spells (Axel 2008), and fertilization that provides important nutrients for maize growth (Muchow and Davis 1988). As the use of solar radiation by crop is influenced by the supporting levels of water and nutrients (Connor et al. 2011), irrigation and fertilization over the eastern part of NCP facilitate the efficient use of radiation by summer maize. Therefore, significant positive correlation is identified between GPP and simultaneous solar radiation at the cropland over the eastern part of NCP (Figs. 3b,h).

Overall, while the importance of solar radiation on photosynthetic activity differs among ecosystems, precipitation is an important precursor for GPP variation on the 20-50-day time scale at all relevant ecosystems.

\section{The impact of 20-50-day precipitation on vegetation productivity over the YYR}

To further confirm the modulation of precipitation on GPP over the YYR on the 20-50-day time scale, daily composites of 20-50-day filtered precipitation anomalies were generated for the selected high GPP

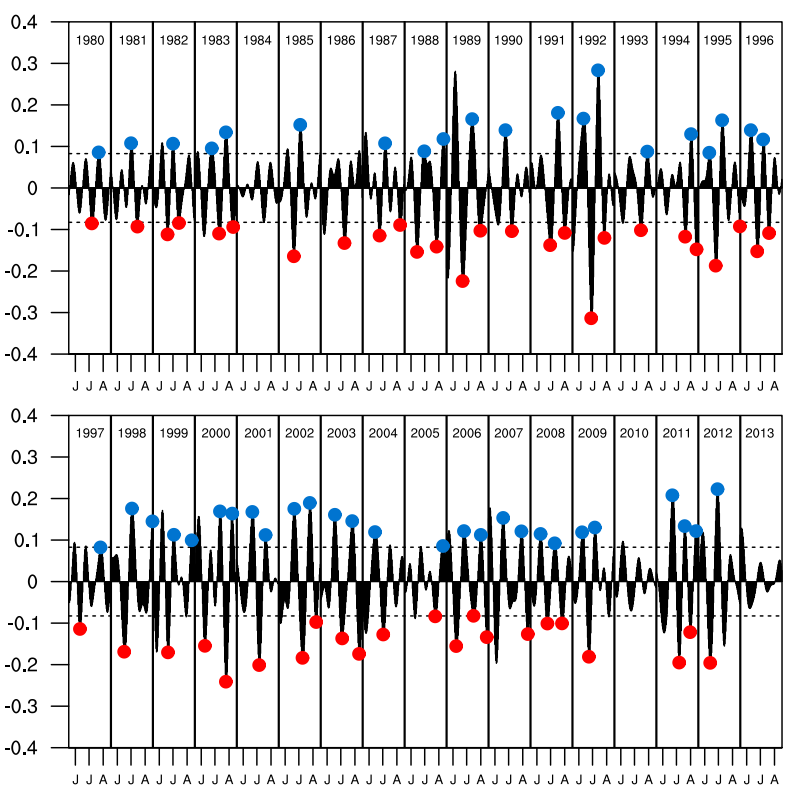

FIG. 4. Time series of GI, defined as the 20-50-day filtered GPP anomalies area averaged over the area between the Yangtze and Yellow Rivers (YYR; $30^{\circ}-40^{\circ} \mathrm{N}, 105^{\circ}-120^{\circ} \mathrm{E}$ ) during the boreal summer (1 Jun-31 Aug) of 1980-2013. The black dashed lines represent plus and minus one standard deviation of GI and show the threshold used to classify high (low) GPP events over the YYR, which are labeled by blue (red) dots. See text for the definitions of high (low) GPP events.

events. The high GPP events represent the cycles during which a significant enhancement of photosynthesis is observed over the YYR, with the maximum GI larger than its standard deviation (denoted by the blue dots in Fig. 4).

On day -21 (Fig. 5a), significant positive precipitation anomalies appear south of the Yangtze River, with the maxima concentrated over the southern part of the middle reaches of the Yangtze River. The zone of positive precipitation anomalies extends to the north of the Yangtze River on day -18 (Fig. 5b), and a new center of positive precipitation anomaly forms over the lower reaches of the Yellow River on day -15 (Fig. 5c). Subsequently, positive precipitation anomalies rapidly develop over the YYR (Fig. 5d) and peak on day -9 , with the maxima in excess of $1.9 \mathrm{~mm} \mathrm{day}^{-1}$ (Fig. 5e). From day -6 (Fig. 5f), the positive precipitation anomalies over the YYR start to decay; meanwhile, negative precipitation anomalies start to propagate northward. On day -3 (Fig. $5 \mathrm{~g}$ ), while positive precipitation anomalies almost disappear over the YYR, negative precipitation anomalies appear north of the Yangtze River. Subsequently, the zone of negative precipitation anomalies spreads northward, occupying most areas of the YYR on day 0 when the GPP 


\section{RAIN Composite}
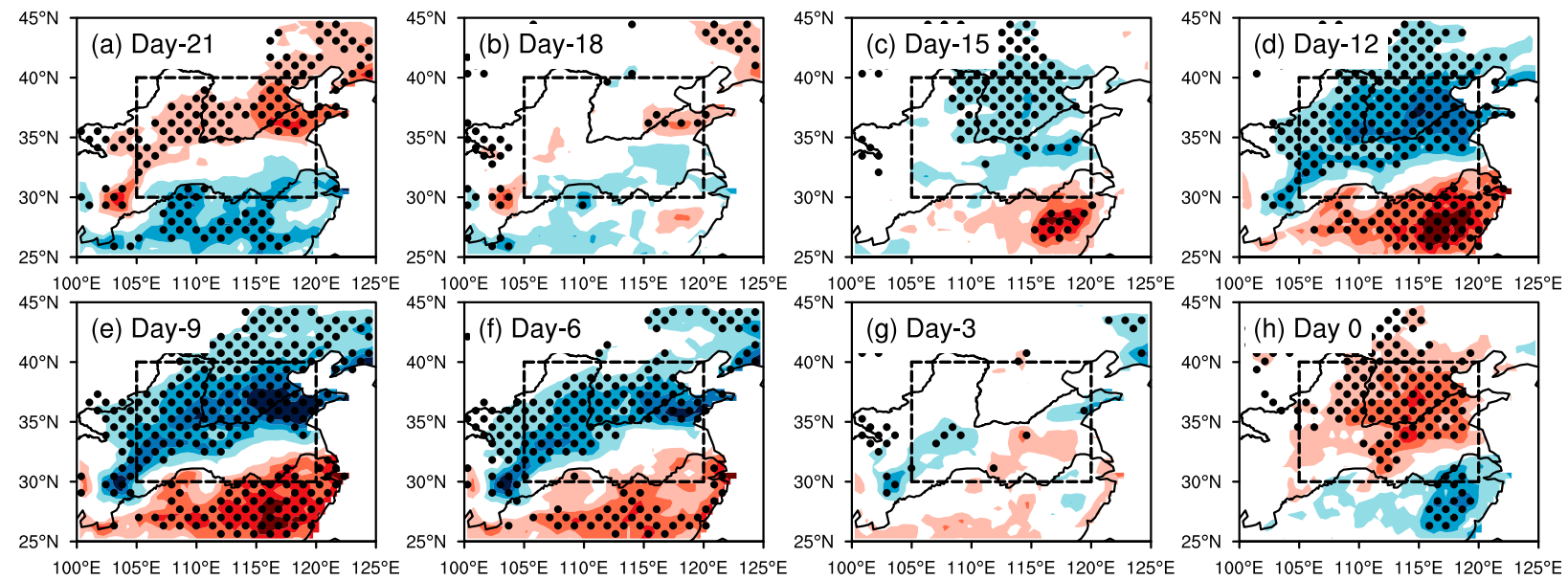

$-1.9$

$-1.4$

$-0.9$

$-0.4$

0.9

1.4

1.9

FIG. 5. Daily composite of 20-50-day filtered precipitation anomalies (shading; $\mathrm{mm} \mathrm{day}^{-1}$ ) over eastern China from day -21 to day 0 with an interval of 3 days during the high GPP events. Stippling indicates the region where the anomalous precipitation is significant at the 95\% confidence level. The thickened contours show the locations of the Yangtze and Yellow Rivers, with the southern contour indicating the Yangtze River and the northern one denoting the Yellow River. The rectangle denotes the area between the Yangtze and Yellow Rivers (YYR; $30^{\circ}-40^{\circ} \mathrm{N}, 105^{\circ}-120^{\circ} \mathrm{E}$ ). See text for the definitions of high GPP events.

anomaly over the YYR is at its peak (Fig. 5h). The strong fluctuations of the 20-50-day precipitation anomalies over the YYR during the cycle of high GPP events indicate that the photosynthetic activity has a close relationship with precipitation change on the 20 50-day time scale. The composite analysis also shows that precipitation leads the GPP by about 9 days, which is consistent with the result of the lag-correlation analysis.

Precipitation influences the water stored in the soil pores through infiltration, and the soil water feeds the vegetation for photosynthesis (Legates et al. 2011). To further understand the lag relationship between the 20-50-day GPP and precipitation anomalies over the YYR, Fig. 6 displays the composite of 20-50-day filtered soil moisture during high GPP events over the YYR. In response to the enhanced precipitation over the YYR on day -15 (Fig. $5 c$ ), soil moisture significantly increases, with positive soil moisture anomalies occupying large areas from the Hetao area to the lower reaches of Yellow River on day -12 (Fig. 6d). Following the further intensification of precipitation during day -12 to day -9 (Figs. $5 \mathrm{~d}-\mathrm{f}$ ), the zone of positive soil moisture anomalies also expands, with the isoline of $1 \times 10^{-2} \mathrm{~m}^{3} \mathrm{~m}^{-3}$ covering most areas of the YYR on day -9 (Fig. 6e). On day -6 , the soil moisture over the YYR reaches the maximum of $2.4 \times 10^{-2} \mathrm{~m}^{3} \mathrm{~m}^{-3}$. Thereafter, as the precipitation over the YYR starts to decrease, the local soil moisture also exhibits a decreasing trend, with the zone of positive soil moisture anomalies gradually decaying (Figs. 6g,h).

The above-described patterns reveal a close relationship between precipitation and the local soil moisture, with precipitation ahead of the local soil moisture by about 3 days on the $20-50$-day time scale. This suggests that the 20-50-day precipitation influences the vegetation productivity via the modulation of the local soil moisture, thereby resulting in the strong 20-50-day fluctuations of GPP over the YYR.

\section{The source of the 20-50-day precipitation anomalies over the YYR}

Previous studies have suggested that the 20-50-day precipitation anomalies over the YYR are caused by a local vertical atmospheric circulation cell between the western North Pacific (WNP; $20^{\circ}-30^{\circ} \mathrm{N}, 125^{\circ}-145^{\circ} \mathrm{E}$ ) and the YYR (Li et al. 2015; Chen and Zhai 2017; Li and Mao 2018a), which is in turn modulated by the northwardpropagating atmospheric ISO over the EASM region (Zhu et al. 2003; Mao et al. 2010; Lee et al. 2013; Qi et al. 2016). As the atmospheric ISO over the EASM area is interconnected with its counterpart over the South Asia summer monsoon region (Lau and Chan 1986; Annamalai and Slingo 2001; Lee et al. 2013), Li et al. (2015) and Chen and Zhai (2017) further suggested that the intraseasonal precipitation anomalies over the YYR are actually associated with the corresponding 


\section{Soil Moisture Composite}

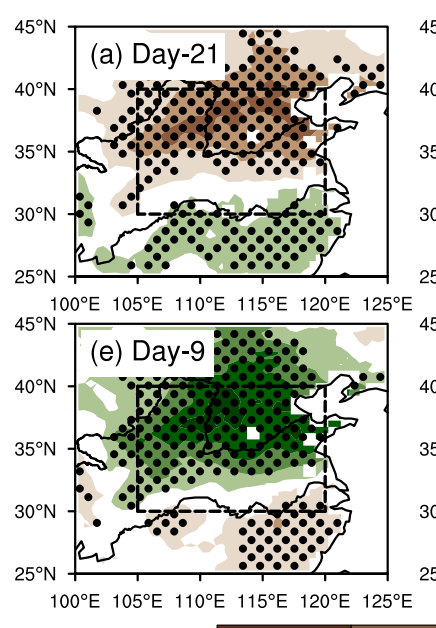

$-2.4$
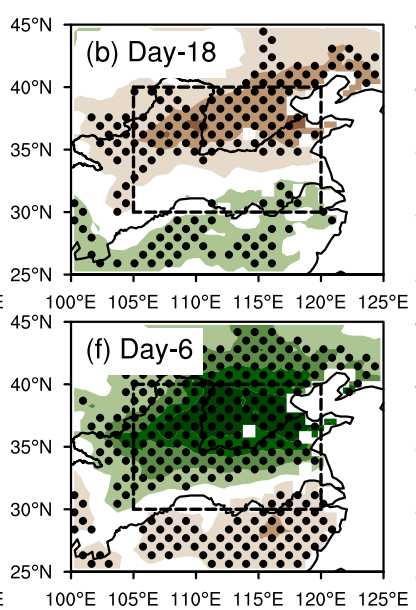

$100^{\circ} \mathrm{E} 105^{\circ} \mathrm{E} 110^{\circ} \mathrm{E} 115^{\circ} \mathrm{E} 120^{\circ} \mathrm{E} 125^{\circ} \mathrm{E}$
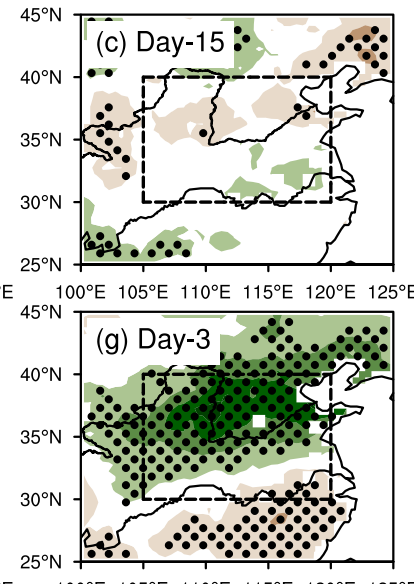

$100^{\circ} \mathrm{E} 105^{\circ} \mathrm{E} 110^{\circ} \mathrm{E} 115^{\circ} \mathrm{E} 120^{\circ} \mathrm{E} 125^{\circ} \mathrm{E}$
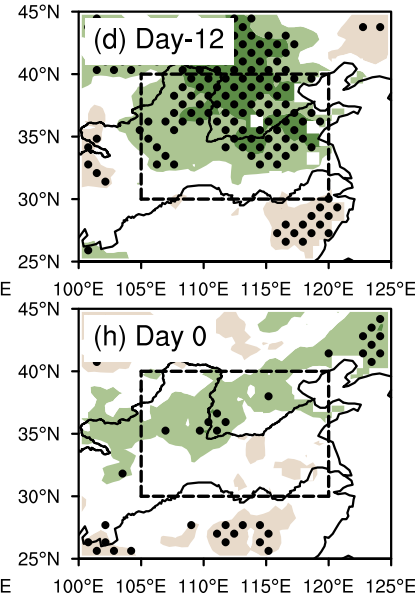

1.7

2.4

FIG. 6. Daily composite of 20-50-day filtered soil moisture anomalies (shading; $10^{-2} \mathrm{~m}^{3} \mathrm{~m}^{-3}$ ) over eastern China from day -21 to day 0 with an interval of 3 days during the high GPP events. Stippling indicates the region where the anomalous soil moisture is significant at the 95\% confidence level. The thickened curves show the locations of the Yangtze and Yellow Rivers, with the southern curve indicating the Yangtze River and the northern one denoting the Yellow River. The rectangular denotes the area between the Yangtze and Yellow Rivers (YYR; $30^{\circ}-40^{\circ} \mathrm{N}, 105^{\circ}-120^{\circ} \mathrm{E}$ ). See text for the definitions of high GPP events.

tropical atmospheric ISO over the entire Asian summer monsoon region.

To examine whether GPP over the YYR is related to the tropical atmospheric ISO, Fig. 7 displays the composite of 20-50-day filtered OLR and 850-hPa wind anomalies. It is evident that there are distinctive and significant preceding signals for GPP over the YYR in convection and circulation anomalies over the tropical oceans. For example, on day -12 (Fig. 7d), strong active convection anomalies are observed over the Arabian Sea-Indian subcontinent and suppressed convection anomalies appear over the equatorial Indian Ocean. The EASM area is predominated by a triple pattern of convection anomalies: significantly suppressed convection and the accompanying anticyclone over the WNP, sandwiched by active convection anomalies over the equatorial western Pacific and the YYR. As the suppressed convection anomalies over the WNP are accompanied by strong divergence anomalies in the lower troposphere and convergence aloft, complementary convergence in the lower troposphere and divergence in the upper troposphere are dynamically induced over the YYR due to the mass continuity (Figs. 8d,1). Therefore, a vertical atmospheric circulation cell is triggered, with the ascending branch located over the YYR and the descending branch located to the south (Fig. 7d). The induced anomalous upward motions serve as a key dynamical condition for positive precipitation anomalies over the YYR. Meanwhile, the anomalous southwesterlies on the northwestern side of the anomalous anticyclone over the WNP enhance the moisture transport to the YYR, providing a favorable thermal and dynamical condition for the increased precipitation. As a result, precipitation significantly increases over the YYR, with the magnitude rising to $1.4 \mathrm{~mm} \mathrm{day}^{-1}$ on day -12 (Fig. $5 \mathrm{~d}$ ) and reaching the maximum on day -9 (Fig. 5e).

With phase evolution, the active convection anomalies over the Indian subcontinent decay, and the suppressed convection anomalies and the accompanying anticyclone over the WNP gradually weaken during the period from day -9 to day -3 (Figs. $7 \mathrm{e}-\mathrm{g}$ ). Active convection anomalies propagate northward from South China Sea (Figs. 7f,g) and occupy the WNP on day 0 instead (Fig. 7h). As a consequence, precipitation over the YYR also exhibits a phase transition from wet to dry (Figs. 5f-h).

The flow pattern and its evolution as shown in Fig. 7 suggest that the key 20-50-day precipitation anomalies over the YYR evolve with the 20-50-day atmospheric ISO over the Asian summer monsoon region, with positive (negative) precipitation anomalies corresponding to the convection pattern of active (suppressed) convection anomalies over the Indian subcontinent and equatorial western Pacific, while suppressed (active) convection anomalies occur over the equatorial Indian Ocean and WNP. This convection pattern highly resembles the typical quadrupole pattern of the atmospheric ISO over the 


\section{OLR \& 850-hPa winds Composite}
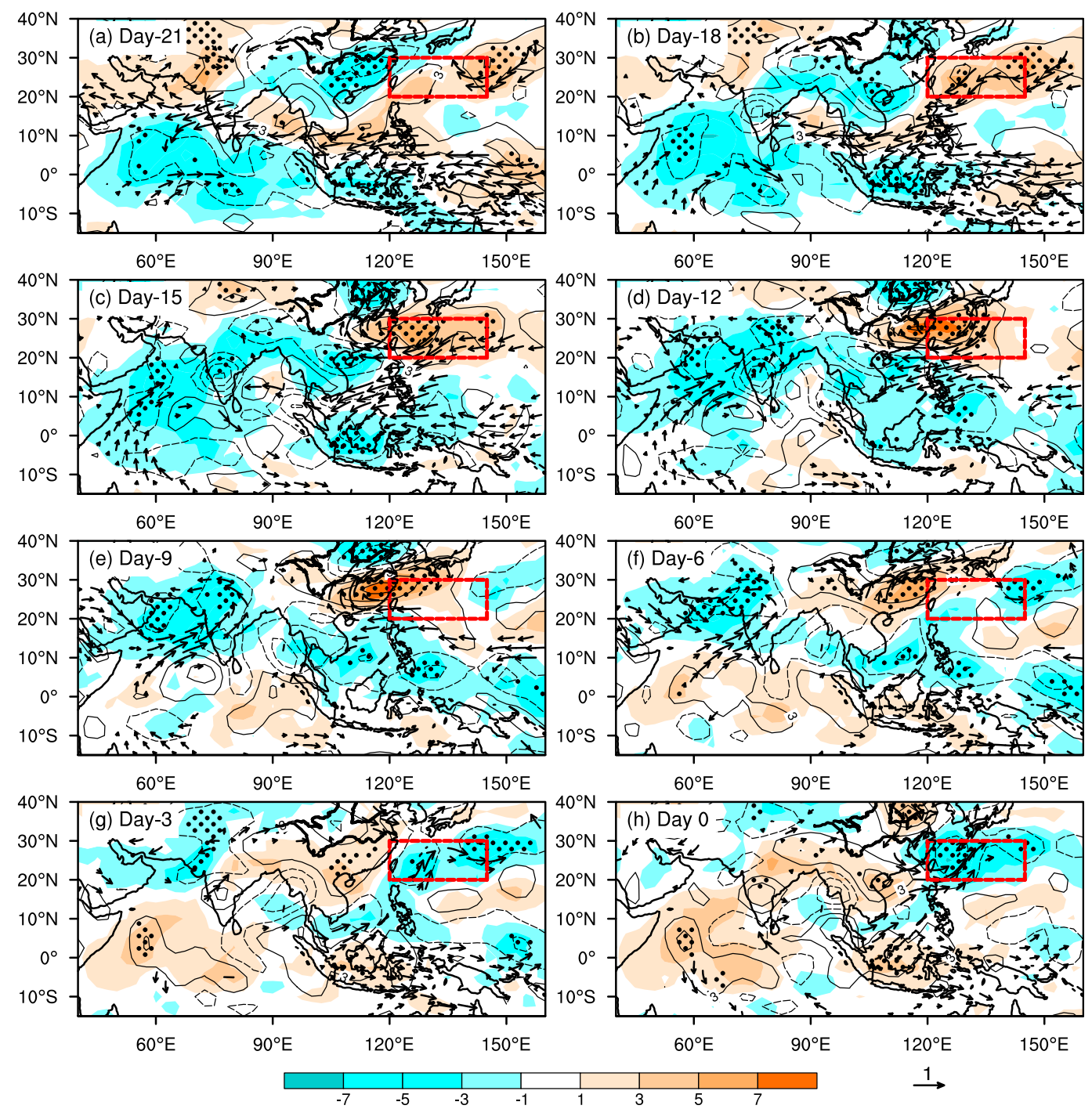

FIG. 7. Daily composite of 20-50-day filtered OLR (color scale; $\mathrm{W} \mathrm{m}^{-2}$ ) and 500-hPa vertical motion (contour; $10^{-3} \mathrm{~Pa} \mathrm{~s}^{-1}$ ) anomalies over the Asian summer monsoon region from day -21 to day 0 with an interval of 3 days during the high GPP events. Stippling indicates the region where both the OLR and 500-hPa vertical motion anomalies are statistically significant at the $90 \%$ confidence level. Also shown are the 20-50-day filtered 850-hPa wind anomalies (vectors; $\mathrm{m} \mathrm{s}^{-1}$ ), in which at least one of the zonal and meridional components is statistically significant at the $90 \%$ confidence level. The thickened curves show the locations of the Yangtze and Yellow Rivers, with the southern curve indicating the Yangtze River and the northern one denoting the Yellow River. The red thickened rectangular denotes the western North Pacific (WNP; $20^{\circ}-30^{\circ} \mathrm{N}, 125^{\circ}-145^{\circ} \mathrm{E}$ ) over which the areaaveraged 20-50-day filtered OLR anomalies are produced in Fig. 9. See text for the definitions of high GPP events.

Asian summer monsoon region (Annamalai and Slingo 2001; Lee et al. 2013). Therefore, it implies that the 20-50-day precipitation anomalies and the consequent 20-50-day fluctuations of GPP over the YYR are indeed associated with the corresponding tropical atmospheric ISO over the Asian summer monsoon region.
Figure 9a demonstrates the leading relationship between 20-50-day convection anomalies over the WNP, induced precipitation and soil moisture anomalies over the YYR, and YYR GPP anomalies during high GPP events, clearly summarizing the process in which the suppressed convection anomalies over the WNP contribute to the increase of GPP over the YYR on the 


\section{Upper-level Div Composite}
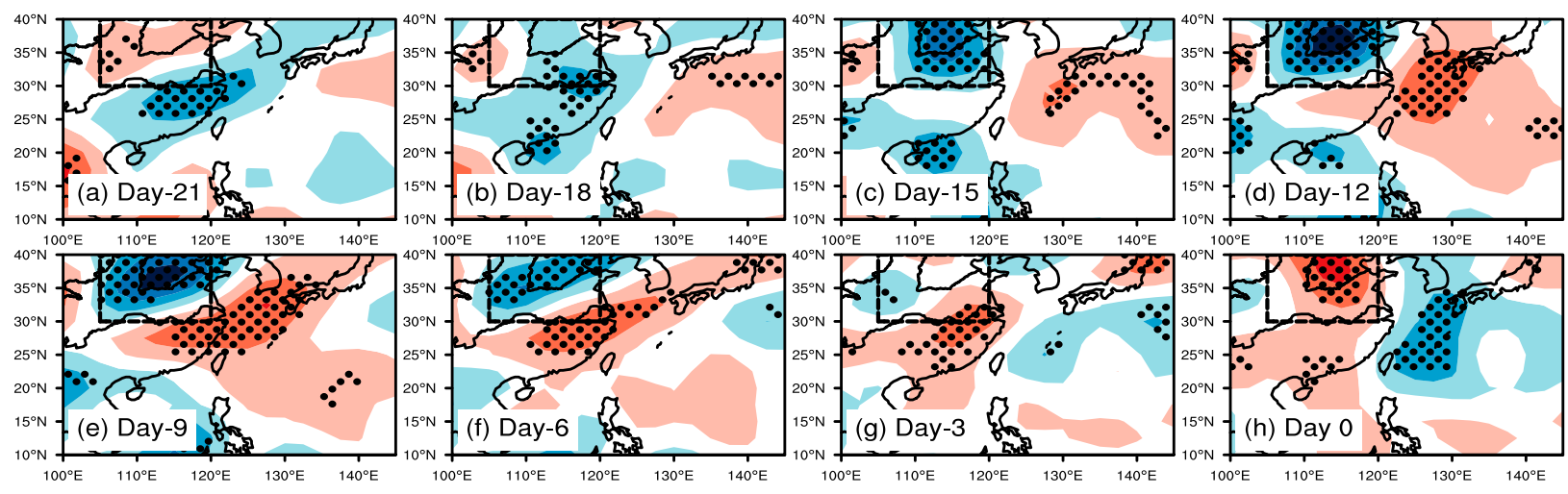

\section{Lower-level Div Composite}

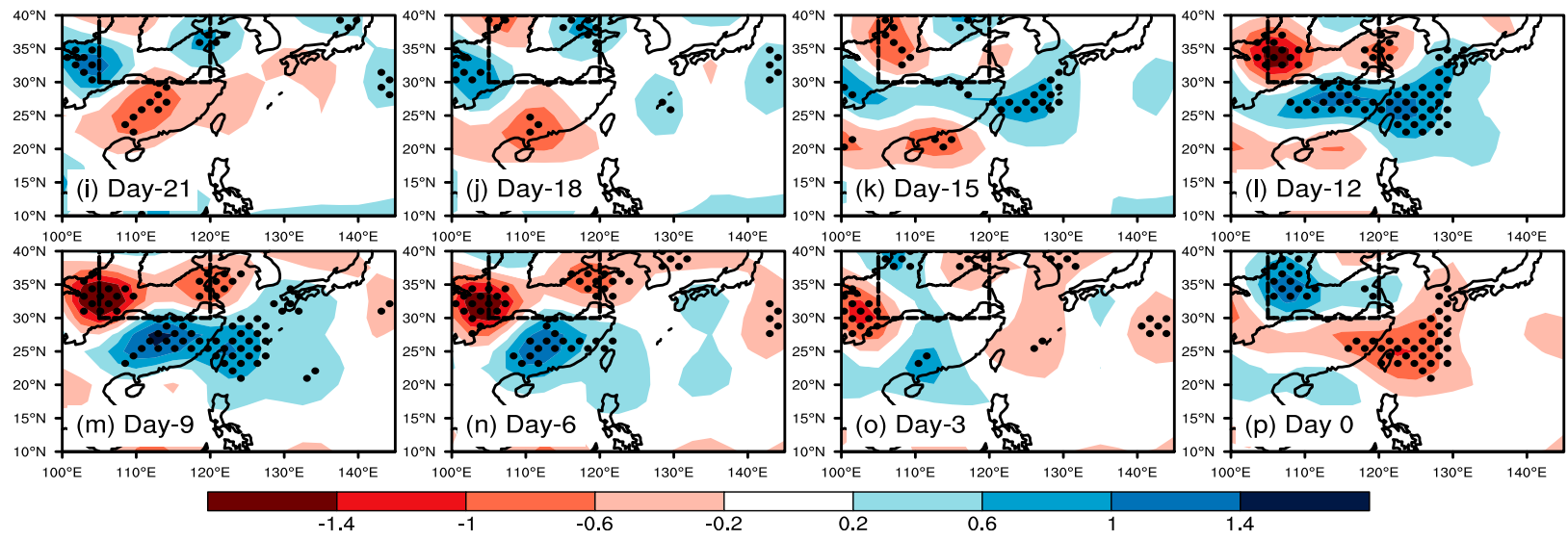

FIG. 8. (a)-(h) Daily composite of 20-50-day filtered 200-hPa divergence (color scale; $10^{-6} \mathrm{~s}^{-1}$ ) anomalies over the East Asian region from day -21 to day 0 with an interval of 3 days during the high GPP events. Stippling indicates the region where 200-hPa divergence anomalies are statistically significant at the $90 \%$ confidence level. The dashed rectangulars denote the area between the Yangtze and Yellow Rivers (YYR; $30^{\circ}-40^{\circ} \mathrm{N}, 105^{\circ}-120^{\circ} \mathrm{E}$ ). The thickened curves show the locations of the Yangtze and Yellow Rivers, with the southern curve indicating the Yangtze River and the northern one denoting the Yellow River. (i)-(p) As in (a)-(h), but for the 925-hPa divergence anomalies.

20-50-day time scale. In contrast, the presence of active convection anomalies over the WNP leads to low GPP events over the YYR (Fig. 9b). As the 20-50-day atmospheric ISO over the Asian summer monsoon region is a major source of the predictability of extended-range forecasting (Lee et al. 2017), the close relationship between the atmospheric ISO and GPP over the YYR suggests the potential for extended-range predictability of vegetation productivity by atmospheric ISO.

\section{Summary and discussion}

The terrestrial ecosystems over East Asia exhibit high carbon uptake, thus playing an important role in the global carbon cycle. As the rich vegetation growth over East Asia mainly benefits from the sufficient water supply brought by the EASM, which is characterized by strong intraseasonal variability, the intraseasonal spatiotemporal variations of GPP in response to the ISO of the EASM have been comprehensively investigated in the present study.

Standard deviations of the intraseasonal GPP were calculated to quantify to the variability of photosynthetic carbon uptake over East Asia on the intraseasonal time scale during the summers of 1980-2013. Strong variability in intraseasonal GPP was identified over the YYR, with a standard deviation of 0.4 $\mathrm{gC} \mathrm{m}^{-2}$ day $^{-1}$. The power spectrum analysis suggested that the 20-50-day ISO is the major component of the intraseasonal GPP anomalies over the YYR, with the most significant power spectra concentrated within the corresponding frequency band. Composite analysis further revealed that the 20-50-day fluctuation of GPP over the YYR is mainly modulated by local 

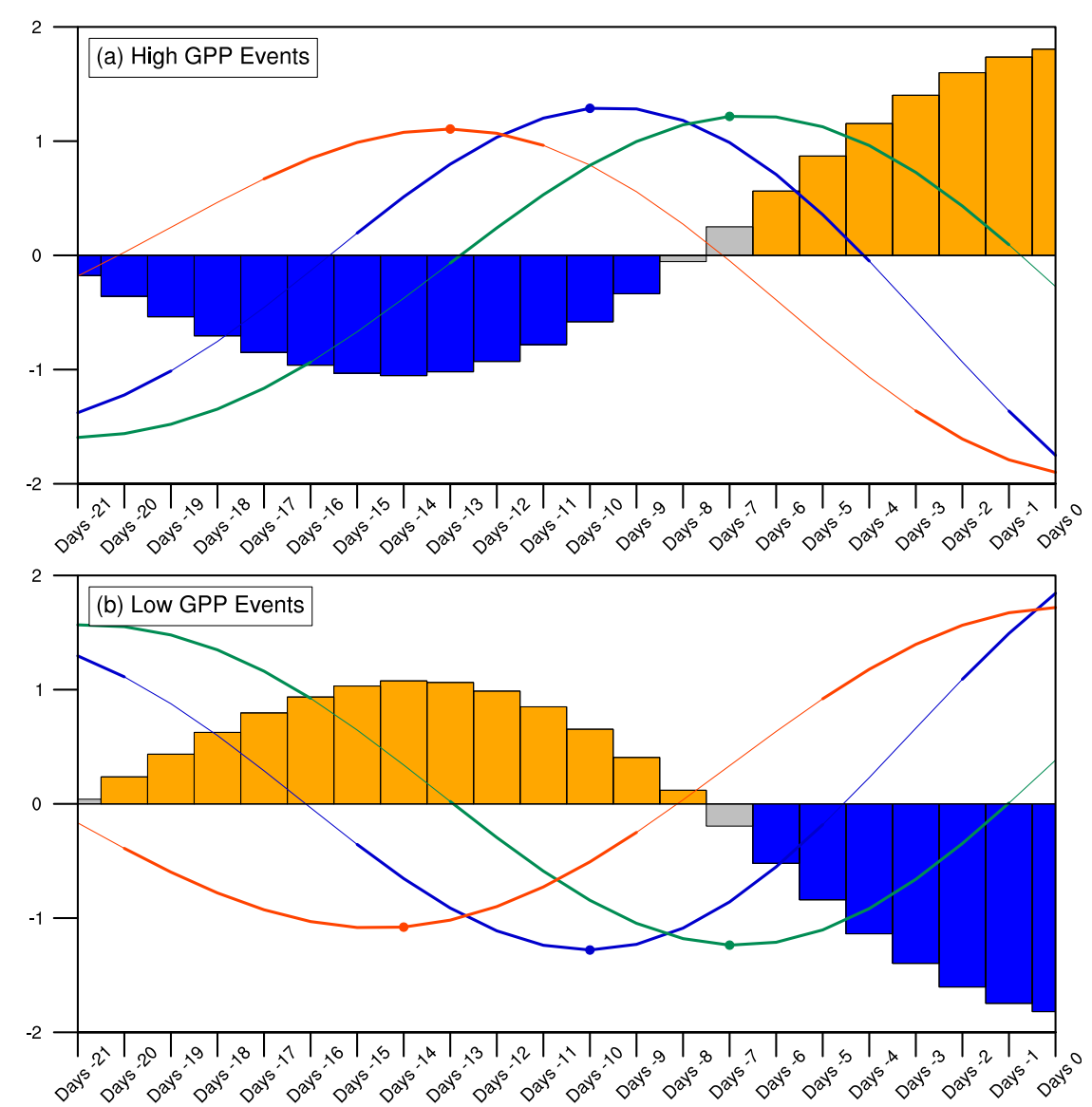

FIG. 9. (a) Time series of the standardized 20-50-day filtered GPP (bars), precipitation (blue line), and soil moisture (green line) anomalies area-averaged over the area between the Yangtze and Yellow Rivers (YYR; $30^{\circ}-40^{\circ} \mathrm{N}, 105^{\circ}-120^{\circ} \mathrm{E}$ ) from day -21 to day 0 (abscissa) during the high GPP events. Also shown is the time series of the standardized 20-50-day filtered OLR anomalies (orange line) area-averaged over the western North Pacific (WNP; $20^{\circ}-30^{\circ} \mathrm{N}, 125^{\circ}-145^{\circ} \mathrm{E}$ ). The colored bars and thickened lines indicate the corresponding anomaly that is significant at the $95 \%$ confidence level. The colored dots denote the maximum of each standardized time series. (b) As in (a), but for the situation of low GPP events, with the colored dots denoting the minimum of each standardized time series. See text for the definitions of high and low GPP events.

precipitation via soil moisture, with precipitation (soil moisture) leading GPP by about 10 (7) days.

The 20-50-day precipitation anomalies over the YYR are in turn related to the atmospheric ISO on the corresponding time scale over the entire Asian summer monsoon area, particular the convective activity over the WNP. When active convection anomalies occur over the Indian subcontinent, Bay of Bengal, Maritime Continent, and equatorial western Pacific, while suppressed convection anomalies occupy the equatorial Indian ocean and WNP, a vertical atmospheric circulation cell is induced between the WNP and the YYR, with the ascending branch over the YYR and the descending branch to the south, thus providing a favorable dynamical condition for increased precipitation over the YYR. Moreover, the anomalous southwesterlies in the lower troposphere enhance the moisture transported northward to the YYR, also contributing to the positive precipitation anomalies. Consequently, 3 days after the formation of such a quadrupole pattern of convection anomaly, precipitation peaks over the YYR. The increased precipitation further enhances the local soil moisture, thus leading to a significant increase of GPP.

Wang et al. (2014) suggests that moisture conditions regulate the response of tropical vegetation growth to temperature variations, indicating that different climatic anomalies may influence the vegetation productivity coordinately. Therefore, the cooperative effect of multiple climatic anomalies on intraseasonal GPP variation 

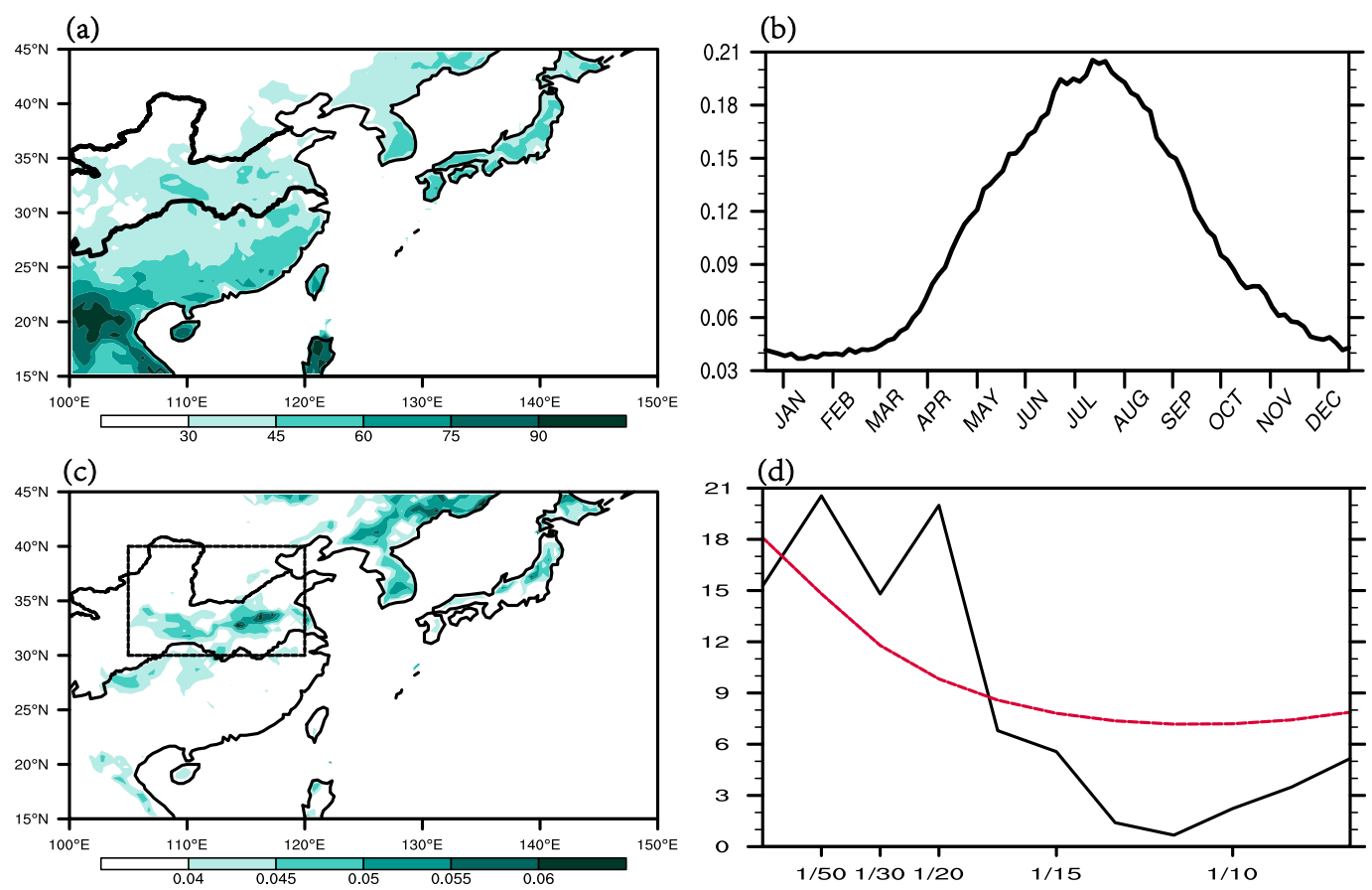

FIG. 10. (a)-(c) As in Figs. 1a-c, but for result of SIF $\left(\mathrm{mW} \mathrm{m}^{-2} \mathrm{~nm}^{-1} \mathrm{sr}^{-1}\right)$ during the period of 2001-13. (d) The mean power spectrum of the intraseasonal SIF over the area between the Yangtze and Yellow Rivers (YYR; $30^{\circ}-$ $40^{\circ} \mathrm{N}, 105^{\circ}-120^{\circ} \mathrm{E}$ ) during the summers of $2001-13$.

demands further investigation in the future. Furthermore, we mainly focus on how natural precipitation, temperature, and solar radiation influence the vegetation productivity over the YYR on the intraseasonal time scale in the present study. As boreal summer is the rainy season for the NCP, with natural precipitation largely sufficient for summer maize and irrigation mainly applied during the period of spring to early summer, it is applicable for the cropland over the eastern part of NCP under the normal conditions. However, the irrigation is applied to guarantee the crop production during severe drought events (Wang et al. 2015). Therefore, a further investigation will be needed to reveal the role of irrigation to fully understand the cause of intraseasonal variation of GPP over the cropland during these extreme events.

Strong 20-50-day fluctuations of GPP are also found at some forest areas south of the Yangtze River, which are also significantly related to the local precipitation and solar radiation (Figs. 3a,b). However, the GPP is negatively correlated with the simultaneous precipitation, while positively correlated with solar radiation. The different relationships between the 20-50-day filtered GPP and precipitation/solar radiation south of the Yangtze River from those at the forest areas over the YYR indicate that the modulation of intraseasonal climatic anomalies on vegetation productivity might differ by latitude. Driving factors for intraseasonal GPP variability south of the Yangtze River demand further study in the future.

As the present analyses are based on the ensemble mean of six versions of FLUXCOM GPP estimates, the same methods have been applied to each version of FLUXCOM GPP to examine the uncertainty in the intraseasonal spatiotemporal variability of photosynthetic carbon uptake derived from different versions of GPP estimates. Results of the six sets are highly consistent with each other, all showing strong intraseasonal fluctuations of vegetation productivity on the target YYR, with 20-50 days as the major periodicity. In all the six GPP estimates, the 20-50-day variation of YYR GPP anomalies is mainly driven by the local 20-50-day precipitation via soil moisture, with precipitation (soil moisture) leading GPP by 9-10 (6-7) days. The uncertainty range of the leading days of precipitation (soil moisture) is small, with only 1 day among the six sets of GPP. Therefore, it suggests that the uncertainty caused by different versions of FLUXCOM GPP is small.

However, due to the relatively short period and sparse coverage of FLUXNET-based flux tower observations over East Asia and bias in the global climate input data, the data-driven daily GPP estimates from FLUXCOM still have some uncertainties (Jung et al. 2017; Zhang et al. 2017), which may further lead to uncertainty in the 

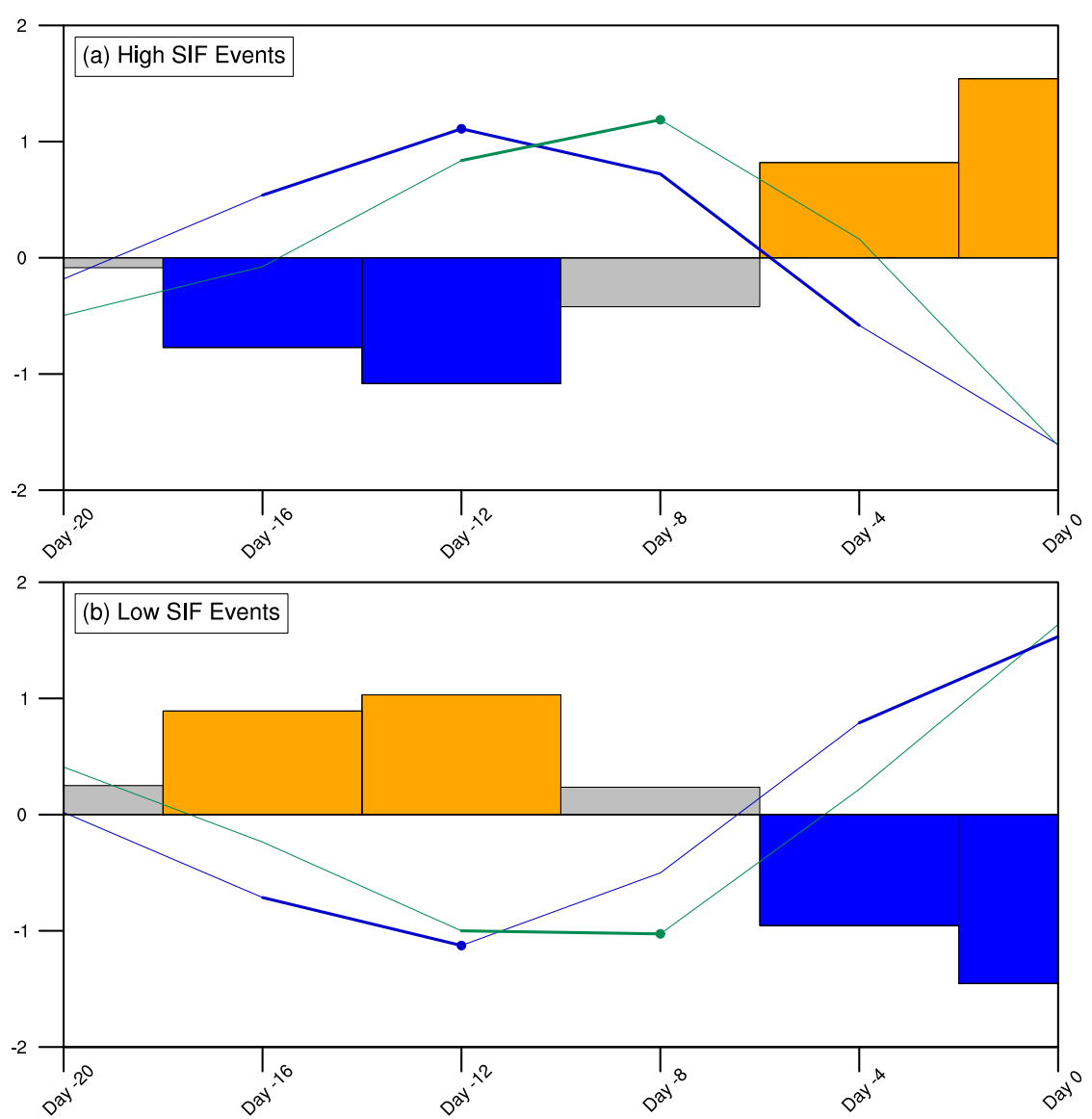

FIG. 11. (a) Time series of the standardized 20-50-day filtered SIF (bars), precipitation (blue line), and soil moisture (green line) anomalies area-averaged over the area between the Yangtze and Yellow Rivers (YYR; $30^{\circ}-40^{\circ} \mathrm{N}, 105^{\circ}-120^{\circ} \mathrm{E}$ ) from day -20 to day 0 with a 4-day interval (abscissa) during the high SIF events. The colored bars and thickened lines indicate the corresponding anomaly that is significant at the $95 \%$ confidence level. The colored dots denote the maximum of each standardized time series. (b) As in (a), but for the situation of low SIF events, with the colored dots denoting the minimum of each standardized time series. See text for the definitions of high and low SIF events.

intraseasonal spatiotemporal variability of vegetation productivity over East Asia. Therefore, the impact of 20-50-day precipitation anomalies on the photosynthetic carbon uptake over the YYR has been also tested based on the SIF data.

Over East Asia, the 4-day-average all-sky SIF is highly consistent with the daily FLUXCOM GPP in terms of spatial distribution and seasonal cycle (Figs. 10a,b). Strong intraseasonal variation of SIF is also identified over the target YYR during the boreal summer (Fig. 10c), with 20-50-day ISO as the major periodicity (Fig. 10d). These results have verified that 20-50-day variation of photosynthetic activity over the YYR is significant and therefore demands investigation.

Similar composites were conducted based on 20-50-day filtered SIF anomalies averaged over the YYR from day -20 to day 0 with an interval of 4 days. A consistent leading relationship between 20-50-day precipitation, soil moisture and SIF anomalies is found during the 17 (19) high (low) SIF events in summers of 2001-13, manifested as positive (negative) precipitation and soil moisture anomalies leading to the increase (decrease) of SIF over the YYR (Fig. 11). Based on the SIF dataset, precipitation (soil moisture) leads the change of SIF by 12 (8) days on the 20-50-day time scale, which is slightly longer (1 or 2 days) than the results from daily FLUXCOM GPP. This change mainly comes from the difference of temporal resolution, since identical time lead is found when we transferred the daily GPP into 4day averages and conducted the composite again. Since the FLUXCOM GPP and SIF data are derived from independent data sources, the remarkable agreement between GPP and SIF dataset in the relationship between precipitation, soil moisture, and photosynthetic 
activity confirms the influence of atmospheric ISO and the resultant precipitation on vegetation productivity over the YYR on the 20-50-day time scale. In the future, numerical experiments based on process-based carbon cycle models need to be conducted to further verify the impact of atmospheric ISO on the photosynthetic carbon uptake over East Asia.

Acknowledgments. Li Jianying was jointly supported by the National Key R\&D Program of China (2018YFC1505904), the National Natural Science Foundation of China (41905076), the Fundamental Research Funds for the Central Universities, and the China University of Geosciences (Wuhan) (CUG170643). J.-S. Kug was supported by the Korea Meteorological Administration Research and Development Program under Grant KMIPA 2018-03212 and the National Research Foundation of Korea (NRF-2018R1A5A1024958). J.-S Kim was supported by the Natural Environment Research Council of United Kingdom through the National Centre for Earth Observation.

\section{REFERENCES}

Anav, A., and Coauthors, 2015: Spatiotemporal patterns of terrestrial gross primary production: A review. Rev. Geophys., 53, 785-818, https://doi.org/10.1002/2015RG000483.

Annamalai, H., and M. Slingo, 2001: Active/break cycles: Diagnosis of the intraseasonal variability of the Asian summer monsoon. Climate Dyn., 18, 85-102, https://doi.org/10.1007/s003820100161.

Axel, T., 2008: Agricultural irrigation demand under present and future climate scenarios in China. Global Planet. Change, 60, 306-326, https://doi.org/10.1016/j.gloplacha.2007.03.009.

Beer, C., and Coauthors, 2010: Terrestrial gross carbon dioxide uptake: Global distribution and covariation with climate. Science, 329, 834-838, https://doi.org/10.1126/ science. 1184984.

Binder, J., S. Graeff, W. Claupein, M. Liu, M. Dai, and P. Wang, 2007: An empirical evaluation of yield performance and water saving strategies in a winter wheat-summer maize double cropping system in the North China Plain. Pflanzenbauwissenschaften: Ger. J. Agron., 11, 1-11.

Breiman, L., 2001: Random forests. Mach. Learn., 45, 5-32, https:// doi.org/10.1023/A:1010933404324.

Chen, R., and R. Lu, 2015: Comparisons of the circulation anomalies associated with extreme heat in different regions of eastern China. J. Climate, 28, 5830-5844, https://doi.org/ 10.1175/JCLI-D-14-00818.1.

Chen, T. C., M. C. Yen, and M. Murakami, 1988: The water vapor transport associated with the 30-50 day oscillation over the Asian monsoon regions during 1979 summer. Mon. Wea. Rev., 116, 1983-2002, https://doi.org/10.1175/15200493(1988)116<1983:TWVTAW>2.0.CO;2.

Chen, Y., and P. Zhai, 2017: Simultaneous modulations of precipitation and temperature extremes in southern parts of China by the boreal summer intraseasonal oscillation. Climate Dyn., 49, 3363-3381, https://doi.org/10.1007/s00382-016-3518-4.

Chen, Z., and Coauthors, 2013: Temperature and precipitation control of the spatial variation of terrestrial ecosystem carbon exchange in the Asian region. Agric. For. Meteor., 182-183, 266-276, https://doi.org/10.1016/j.agrformet.2013.04.026.

Connor, D. J., R. S. Loomis, and K. G. Cassman, 2011: Crop Ecology: Productivity and Management in Agricultural Systems. Cambridge University Press, 546 pp.

Cox, P., and C. Jones, 2008: Illuminating the modern dance of climate and $\mathrm{CO}_{2}$. Science, 321, 1642-1644, https://doi.org/ 10.1126/science. 1158907.

Ding, Y. H., and J. C. L. Chan, 2005: The East Asian summer monsoon: An overview. Meteor. Atmos. Phys., 89, 117-142, https://doi.org/10.1007/s00703-005-0125-z.

Frank, D., and Coauthors, 2015: Effects of climate extremes on the terrestrial carbon cycle: Concepts, processes and potential future impacts. Global Change Biol., 21, 2861-2880, https:// doi.org/10.1111/gcb.12916.

Genty, B., J. M. Briantais, and N. R. Baker, 1989: The relationship between the quantum yield of photosynthetic electron transport and quenching of chlorophyll fluorescence. Biochim. Biophys. Acta, 990, 87-92, https://doi.org/ 10.1016/S0304-4165(89)80016-9.

Harris, I., and Coauthors, 2014: Updated high-resolution grids of monthly climatic observations-The CRU TS3.10 dataset. Int. J. Climatol., 34, 623-642, https://doi.org/10.1002/joc.3711.

Haykin, S., 1998: Neural Networks: A Comprehensive Foundation. Prentice Hall, 842 pp.

He, J., P. Zhao, C. Zhu, R. Zhang, X. Tang, L. Chen, and X. Zhou, 2008: Discussion of some problems as to the East Asian subtropical monsoon. J. Meteor. Res., 22, 419-434., http://www.cmsjournal.net: 8080/Jweb_jmr/EN/abstract/abstract1155.shtml.

He, Y., and Coauthors, 2007: Terrestrial growth in China and its relationship with climate based on the MODIS data. Acta Ecol. Sin., 27, 5086-5092, https://doi.org/10.1016/ S1872-2032(08)60015-3.

Hirata, R., and Coauthors, 2008: Spatial distribution of carbon balance in forest ecosystems across East Asia. Agric. For. Meteor. 148, 761-775, https://doi.org/10.1016/j.agrformet.2007.11.016.

Hsu, P.-C., J.-Y. Lee, K.-J. Ha, and C.-H. Tsou, 2017: Influences of boreal summer intraseasonal oscillation on heat waves in monsoon Asia. J. Climate, 30, 7191-7211, https://doi.org/ 10.1175/JCLI-D-16-0505.1.

Hu, W. T., A. M. Duan, Y. Li, and H. He, 2016: The intraseasonal oscillation of eastern Tibetan Plateau precipitation in response to the summer Eurasian wave train. J. Climate, 29, 7215-7230, https://doi.org/10.1175/JCLI-D-15-0620.1.

Jung, M., and Coauthors, 2017: Compensatory water effects link yearly global land $\mathrm{CO}_{2}$ sink changes to temperature. Nature, 541, 516-520, https://doi.org/10.1038/nature20780.

Kanamitsu, M., and Coauthors, 2002: NCEP dynamical seasonal forecast system 2000. Bull. Amer. Meteor. Soc., 83, 1019-1037, https:// doi.org/10.1175/1520-0477(2002)083<1019:NDSFS > 2.3.CO;2.

Kobayashi, S., and Coauthors, 2015: The JRA-55 reanalysis: General specifications and basic characteristics. J. Meteor. Soc. Japan, 93, 5-48, https://doi.org/10.2151/jmsj.2015-001.

Kondo, M., T. M. Saitoh, H. Sato, and K. Ichii, 2017: Comprehensive synthesis of spatial variability in carbon flux across monsoon Asian forests. Agric. For. Meteor., 232, 623-634, https://doi.org/ 10.1016/j.agrformet.2016.10.020.

Krause, G. H., and E. Weis, 1991: Chlorophyll fluorescence and photosynthesis: The basics. Annu. Rev. Plant Physiol., 42, 313349, https://doi.org/10.1146/annurev.pp.42.060191.001525.

Lasslop, G., and Coauthors, 2010: Separation of net ecosystem exchange into assimilation and respiration using a light response curve approach: Critical issues and global evaluation. 
Global Change Biol., 16, 187-208, https://doi.org/10.1111/ j.1365-2486.2009.02041.x.

Lau, K.-M., and P. H. Chan, 1986: Aspects of the 40-50 day oscillation during the northern summer as inferred from outgoing longwave radiation. Mon. Wea. Rev., 114, 1354-1367, https://doi.org/ 10.1175/1520-0493(1986)114<1354:AOTDOD>2.0.CO;2.

- G. J. Yang, and S. H. Shen, 1988: Seasonal and intraseasonal climatology of summer monsoon precipitation over East Asia Mon. Wea. Rev., 116, 18-37, https://doi.org/10.1175/15200493(1988) $116<0018$ :SAICOS $>2.0$. CO;2.

Lee, J. Y., and Coauthors, 2013: Real-time multivariate indices for the boreal summer intraseasonal oscillation over the Asian summer monsoon region. Climate Dyn., 40, 493-509, https:// doi.org/10.1007/s00382-012-1544-4.

Lee, S. S., J. Moon, B. Wang, and H. Kim, 2017: Subseasonal prediction of extreme precipitation over Asia: Boreal summer intraseasonal oscillation perspective. J. Climate, 30, 28492865, https://doi.org/10.1175/JCLI-D-16-0206.1.

Legates, D. R., R. Mahmood, D. F. Levia, T. L. DeLiberty, S. M. Quiring, C. Houser, and F. E. Nelson, 2011: Soil moisture: A central and unifying theme in physical geography. Prog. Phys. Geogr., 35, 65-86, https://doi.org/10.1177/0309133310386514.

Le Quéré, C., and Coauthors, 2018: Global carbon budget 2018. Earth Syst. Sci. Data, 10, 2141-2194, https://doi.org/10.5194/ essd-10-2141-2018.

Li, J. Y., and J. Mao, 2018a: Impact of the 30-60-day boreal summer intraseasonal oscillation over the Asian summer monsoon region on persistently extreme precipitation over eastern China. Chin. J. Atmos. Sci., 43, 796-812.

$\ldots$, and _ 2018b: The impact of interactions between tropical and midlatitude intraseasonal oscillations around the Tibetan Plateau on the 1998 Yangtze floods. Quart. J. Roy. Meteor. Soc., 144, 1123-1139, https://doi.org/10.1002/qj.3279.

,-- , and G. Wu, 2015: A case study of the impact of boreal summer intraseasonal oscillations on Yangtze rainfall. Climate Dyn., 44, 2683-2702, https://doi.org/10.1007/s00382-014-2425-9.

Li, R. C. Y., and W. Zhou, 2015: Multiscale control of summertime persistent heavy precipitation events over South China in association with synoptic, intraseasonal, and low-frequency background. Climate Dyn., 45, 1043-1057, https://doi.org/ 10.1007/s00382-014-2347-6.

Liebman, B., and C. A. Smith, 1996: Description of a complete (interpolated) outgoing longwave radiation dataset. Bull. Amer. Meteor. Soc., 77, 1275-1277.

Mao, J., Z. Sun, and G. Wu, 2010: 20-50-day oscillation of summer Yangtze rainfall in response to intraseasonal variations in the subtropical high over the western North Pacific and South China Sea. Climate Dyn., 34, 747-761, https://doi.org/10.1007/ s00382-009-0628-2.

Martens, B., and Coauthors, 2017: GLEAM v3: Satellite-based land evaporation and root-zone soil moisture. Geosci. Model Dev., 10, 1903-1925, https://doi.org/10.5194/gmd-101903-2017.

Muchow, R. C., and R. Davis, 1988: Effect of nitrogen supply on the comparative productivity of maize and sorghum in a semiarid tropical environment II. Radiation interception and biomass accumulation. Field Crops Res., 18, 17-30, https:// doi.org/10.1016/0378-4290(88)90056-1.

New, M., M. Hulme, and P. Jones, 2000: Representing twentiethcentury space-time climate variability. Part II: Development of 1901-96 monthly grids of terrestrial surface climate. J. Climate, 13, 2217-2238, https://doi.org/10.1175/15200442(2000)013<2217:RTCSTC > 2.0.CO;2.
Pan, Y., and Coauthors, 2011: A large and persistent carbon sink in the world's forests. Science, 333, 988-993, https://doi.org/ 10.1126/science.1201609.

Pearcy, R. W., J. P. Krall, and G. F. Sassenrath-Cole, 1996: Photosynthesis in fluctuating light environments. Photosynthesis and the Environment, N. R. Baker, Ed., Springer, 321-346.

Piao, S., J. Fang, P. Ciais, P. Peylin, Y. Huang, S. Sitch, and T. Wang, 2009: The carbon balance of terrestrial ecosystems in China. Nature, 458, 1009-1013, https://doi.org/10.1038/ nature 07944.

Qi, Y. J., R. H. Zhang, and T. Li, 2016: Structure and evolution characteristics of atmospheric intraseasonal oscillation and its impact on the summer rainfall over the Yangtze River basin in 1998. Chin. J. Atmos. Sci., 40, 451-462.

Reichstein, M., and Coauthors, 2005: On the separation of net ecosystem exchange into assimilation and ecosystem respiration: Review and improved algorithm. Global Change Biol., 11, 1424-1439, https://doi.org/10.1111/j.1365-2486.2005.001002.x.

- and Coauthors, 2013: Climate extremes and the carbon cycle. Nature, 500, 287-295, https://doi.org/10.1038/nature12350.

Tramontana, G., and Coauthors, 2016: Predicting carbon dioxide and energy fluxes across global FLUXNET sites with regression algorithms. Biogeosciences, 13, 4291-4313, https://doi.org/ 10.5194/bg-13-4291-2016.

University of East Anglia Climatic Research Unit, 2019: CRU JRA v1.1: A forcings dataset of gridded land surface blend of Climatic Research Unit (CRU) and Japanese reanalysis (JRA) data; Jan. 1901-Dec. 2017. Centre for Environmental Data Analysis, accessed 2019, https://doi.org/10.5285/ 13f3635174794bb98cf8ac4b0ee8f4ed.

Valsala, V., Y. K. Tiwari, P. Pillai, M. Roxy, S. Maksyutov, and R. Murtugudde, 2013: Intraseasonal variability of terrestrial biospheric $\mathrm{CO}_{2}$ fluxes over India during summer monsoons. J. Geophys. Res. Biogeosci., 118, 752-769, https://doi.org/ 10.1002/jgrg.20037.

Wang, J., and Coauthors, 2015: Information provision, policy support, and farmers' adaptive responses against drought: An empirical study in the North China Plain. Ecol. Modell., 318, 275-282, https://doi.org/10.1016/j.ecolmodel.2014.12.013.

Wang, X. H., and Coauthors, 2014: A two-fold increase of carbon cycle sensitivity to tropical temperature variations. Nature, 506, 212-215, https://doi.org/10.1038/nature12915.

Yang, S. Y., and T. Li, 2017: Causes of intraseasonal diabatic heating variability over and near the Tibetan Plateau in boreal summer. Climate Dyn., 49, 2385-2406, https://doi.org/10.1007/ s00382-016-3463-2.

Yao, Y. T., and Coauthors, 2018: Spatiotemporal pattern of gross primary productivity and its covariation with climate in China over the last thirty years. Global Change Biol., 24, 184-196, https://doi.org/10.1111/gcb.13830.

Yu, G.-R., and Coauthors, 2013: Spatial patterns and climate drivers of carbon fluxes in terrestrial ecosystems of China. Global Change Biol., 19, 798-810, https://doi.org/10.1111/ gcb.12079.

Z. Chen, S. Piao, C. Peng, P. Ciais, Q. Wang, X. Li, and X. Zhu, 2014: High carbon dioxide uptake by subtropical forest ecosystems in the East Asian monsoon region. Proc. Natl. Acad. Sci. USA, 111, 4910-4915, https://doi.org/10.1073/ pnas.1317065111.

Zhang, L., and Coauthors, 2019: Interannual variability of terrestrial net ecosystem productivity over China: Regional contributions and climate attribution. Environ. Res. Lett., 14, 014003, https://doi.org/10.1088/1748-9326/aaec95. 
Zhang, Y., X. Xiao, X. Wu, S. Zhou, G. Zhang, Y. Qin, and J. Dong, 2017: A global moderate resolution dataset of gross primary production of vegetation for 2000-2016. Sci. Data, 4, 170165, https://doi.org/10.1038/sdata.2017.165.

_, and Coauthors, 2018: A global spatially contiguous solarinduced fluorescence (CSIF) dataset using neural networks. Biogeosciences, 15, 5779-5800, https://doi.org/10.5194/bg-155779-2018.
Zhu, C., T. Nakazawa, J. Li, and L. Chen, 2003: The 30-60 day intraseasonal oscillation over the western North Pacific Ocean and its impacts on summer flooding in China during 1998. Geophys. Res. Lett., 30, 1952, https://doi.org/10.1029/2003GL017817.

, X. Zhou, P. Zhao, L. Chen, and J. He, 2011: Onset of East Asian subtropical summer monsoon and rainy season in China. Sci. China Earth Sci., 54, 1845-1853, https://doi.org/ 10.1007/s11430-011-4284-0. 